\title{
The dynamics of idealized katabatic flow over a moderate slope and ice shelf
}

\author{
By IAN A. RENFREW* \\ British Antarctic Survey, Cambridge, UK
}

(Received 5 February 2003; revised 16 October 2003)

\begin{abstract}
SUMMARY
A non-hydrostatic numerical weather prediction model has been employed to simulate idealized katabatic flows over a moderate slope and adjoining ice shelf. The topography of Coats Land and the adjoining Brunt Ice Shelf, Antarctica, has been used; this is typical of much of the Antarctic coastline. The Regional Atmospheric Modeling System Version 4.3 has been adapted for simulations over compacted snow, most notably through changes to the multi-layer soil model. The simulations are initialized using clear-sky conditions and at rest. On the slope, a shallow katabatic flow develops, the winds becoming approximately steady on the slope by $\sim 12 \mathrm{~h}$. The peak downslope winds are about $7 \mathrm{~m} \mathrm{~s}^{-1}$ at $30 \mathrm{~m}$ above the snow surface. The katabatic flow depth ranges from 50 to $100 \mathrm{~m}$ down the slope. Over the ice shelf the katabatic flow peters out, while a pool of cold air develops, primarily through sensible-heat loss into the surface and partially balancing the net radiative-heat loss to space. Near-surface and sounding data from the model simulations compare well with archetypal and typical katabatic flow observations, especially after some tuning of the model's turbulence parametrization.

An analysis of the downslope flow dynamics shows the buoyancy force is generally balanced by the inertial force, except towards the foot of the slope where it is balanced by upslope forces related to gradients in the potential-temperature deficit and katabatic-layer height, caused by the pool of cold air over the ice shelf. Over time, the cooling of the ice shelf boundary layer leads to an apparent retreat of the katabatic flow from the ice shelf and some way up the slope. The dynamical analysis explains the surface climatology observed, such that the persistent katabatic winds of Coats Land rarely reach the Brunt Ice Shelf. The simulated katabatic flow moves from 'shooting' to 'tranquil' towards the foot of the slope. This transition acts to trigger a train of internal gravity waves which propagate energy upwards away from the katabatic flow jump. Previous studies have also found shooting to tranquil katabatic flow transitions, so to generalize these findings would suggest that internal gravitywave generation is ubiquitous around much of coastal Antarctica and Greenland.
\end{abstract}

\begin{abstract}
KeYwords: Antarctica Downslope winds Hydraulic jump Internal gravity waves Mesoscale model RAMS
\end{abstract}

\section{INTRODUCTION}

Katabatic winds are downslope buoyancy-driven flows. Over Antarctica and Greenland, the high latitude location leads to a net radiative loss to space during winter which cools the snow surface and overlying atmosphere, and thus generates widespread katabatic flows due to the domed topography. This ubiquity means that katabatic winds play an important part in the atmospheric general circulation at high latitudes (e.g. Parish and Bromwich 1991, 1998) and so a detailed understanding of their dynamics is important for a complete understanding of the high-latitude climate system. A number of studies have focused upon the climatologically extreme katabatic winds that occur in areas of very steep and confluent topography, for example in the Terra Nova Bay region (e.g. Parish and Waight 1987; Bromwich 1989; Parish and Bromwich 1989), or near Siple Coast (e.g. Bromwich and Liu 1996). Seemingly less attention has been paid to more moderate katabatic winds in the Antarctic, with some exceptions (e.g. Heinemann 1997; Gallée and Pettré 1998).

In this study, the focus is on 'ordinary' katabatic flows, that is to say those that occur over topography that is more typical of coastal Antarctica: relatively modest in slope (maximum $\sim 5 \%$ ) and uniform across the slope. To be specific, the focus is on Coats Land and the adjoining Brunt Ice Shelf, as this was the subject of a recent climatological study that raised a number of interesting questions pertinent to much of coastal Antarctica and Greenland. Renfrew and Anderson (2002) examined 5 years

\footnotetext{
* Corresponding address: Physical Sciences Division, British Antarctic Survey, Natural Environment Research Council, High Cross, Madingley Road, Cambridge CB3 0ET, UK. e-mail: i.renfrew@bas.ac.uk

(C) Royal Meteorological Society, 2004.
} 


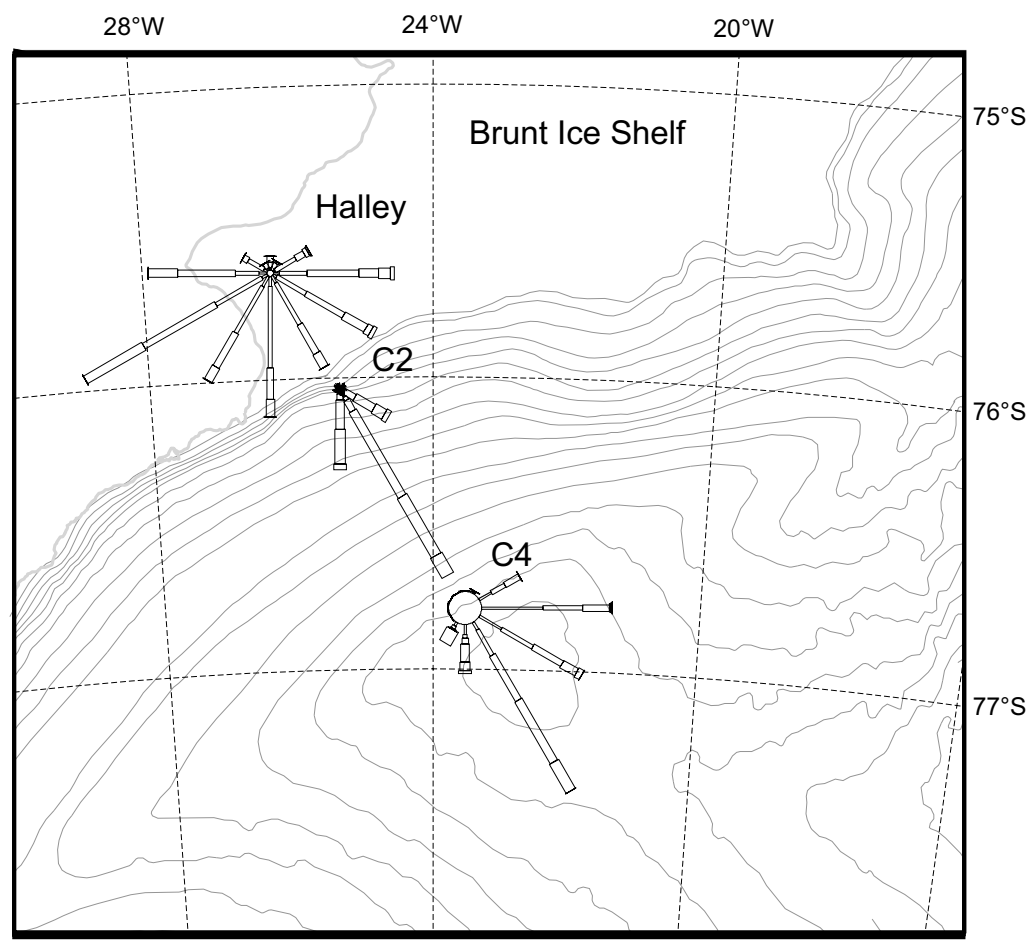

Figure 1. A topographic map of Coats Land, Antarctica, based on the Antarctic Digital Database version 3. The contour interval is $100 \mathrm{~m}$. Overlaid are surface wind roses at Halley and the automatic weather station sites $\mathrm{C} 2$ and $\mathrm{C} 4$, compiled for times when conditions were katabatic at C2-adapted from Renfrew and Anderson (2002). The wind directions are in $30^{\circ}$ bins and the wind speeds in $5 \mathrm{~m} \mathrm{~s}^{-1}$ bins from 0.1 to $30 \mathrm{~m} \mathrm{~s}^{-1}$. The size of the centre circle is proportional to the number of calm observations.

of automatic weather station (AWS) data, supplemented by synoptic and upper-air sounding observations from Halley research station $\left(75.6^{\circ} \mathrm{S}, 26.2^{\circ} \mathrm{W}\right)$, and infrared satellite observations. A basic climatological analysis revealed two different dynamical regimes in the region. Over the ice shelf near-surface winds were usually from the east, occasionally from the west; whereas over the continental slopes winds were from the east-to-south quadrant. Excluding the summer months, the ice shelf surface layer was about $10 \mathrm{~K}$ colder in terms of potential temperature than over the continent, and was more stable than on the steepest part of the slope. Motivated by case-studies and theoretical arguments, a conditional sampling method was used to select a subset of the AWS data that were, in some sense, katabatic*. Examining these data, Renfrew and Anderson (2002) showed that these archetypal katabatic winds flow from around $10^{\circ}$ to the east of the fall line, with near-surface wind speeds of $7.5 \mathrm{~m} \mathrm{~s}^{-1}$ at the steepest part of the slope, and $5.1 \mathrm{~m} \mathrm{~s}^{-1}$ higher up (see Fig. 1). Interestingly, they found no coherent surface katabatic flow signature over the Brunt Ice Shelf, an aspect of the local climate also discussed by King (1993). Renfrew and Anderson (2002) found that during katabatic conditions potential temperatures over the ice shelf were also, on average, some $10 \mathrm{~K}$ lower than over the continent. They therefore hypothesized that damming due to this pool of cold air in the ice shelf boundary layer was causing the katabatic winds flowing from the continental slopes to ride over the boundary layer and/or be dissipated

\footnotetext{
* The selection procedure chooses wintertime data where the perturbation pressure gradient between the AWS and Halley is small and the surface-layer stability is large-see Renfrew and Anderson (2002) for details.
} 
in some way as the flow decelerates (e.g. Ball 1960; Gallée and Schayes 1992; Gallée and Pettré 1998; Heinemann 1999). This study investigates the dynamics of katabatic winds over Coats Land and, as a consequence, this hypothesis. The results are pertinent to all ordinary katabatic flows, i.e. those over moderate and uniform slopes; in other words, much of coastal Antarctica and Greenland. The simulations reveal several new facets of katabatic flow dynamics that, due to their generic nature, have relevance to the entire Antarctic climate system.

To investigate the dynamics of Coats Land katabatic winds a state-of-the-art numerical weather prediction (NWP) model, the Regional Atmospheric Modeling System (RAMS) is utilized. A series of idealized model experiments are carried out using a topographic slice of Coats Land (Fig. 1). The simulations are initialized with infrared brightness temperatures at the snow surface and a homogeneous atmosphere at rest. A coherent downslope flow develops over the first few hours of model simulation, becoming quasi steady-state by $\sim 12 \mathrm{~h}$. In section 2 , the model and its configuration are described in more detail and compared with previous katabatic modelling studies. In section 3, the basic flow response is illustrated and discussed, while in section 4 the results are validated against archetypal and typical surface and sounding observations. In section 5, the dynamics of the downslope flow are investigated through an analysis of the momentum budget, and section 6 concludes the paper.

\section{THE NUMERICAL MODELLING OF KATABATIC WINDS}

Numerical models have been widely used to study katabatic flows, and meet with reasonable success if sufficient vertical resolution is used. A great many of these numerical studies have been idealized, in the sense that the NWP model is initialized with a prescribed atmosphere rather than from a model analysis. Early studies (e.g. Parish 1984; Parish and Waight 1987; Gallée and Schayes 1992) solved the hydrostatic primitive equations with relatively simple treatments of the key physical processes, namely the surface boundary conditions, and the parametrizations of radiation and turbulence. For example, they usually used a force-restore prognostic equation for the surface temperature. Over time more sophisticated parametrizations have been included, for example, a multi-layer 'soil' model (Gallée and Duynkerke 1997; Heinemann 1997) and a non-hydrostatic model configuration (e.g. Cassano and Parish 2000). Relatively coarse grids $(\sim 20 \mathrm{~km})$ have been used to simulate regional-scale or continental-scale flows and study, for example: the general circulation of the southern hemisphere (Parish and Bromwich 1991); seasonal differences in flow evolution (Heinemann 1997; Van den Broeke et al. 2002); and the gross momentum budget (Van den Broeke et al. 2002). Finer grids ( $\sim 2 \mathrm{~km}$ ) have been used to study, for example: the topographic modification of downslope flow (Parish 1984; Gallée and Schayes 1994; Parish 2001); the influence of the background synoptic-scale conditions (Gallée and Pettré 1998; Parish 2001); and interactions with polynyas (Gallée 1997). This study falls into the second grouping, that of fine-scale modelling, and advances the progress made by Parish and Waight (1987), Gallée and Schayes (1992), and Bromwich et al. (1994).

The RAMS model is a state-of-the-art highly flexible meteorological modelling system designed to carry out simulations from the microscale to the global-scale. The model is based on the non-hydrostatic, compressible primitive equations, along with conservation equations for scalar quantities such as water vapour (e.g. Pielke et al. 1992; Pielke 2002). There are numerous choices available for boundary conditions and physical parametrizations (see Pielke (2002) and references therein). Table 1 summarizes the basic model configuration and physical parametrizations used in this study. 
TABLE 1. A SUMMARY OF THE BASIC RAMS ${ }^{1}$ CONFIGURATION USED IN THIS STUDY

\begin{tabular}{|c|c|c|}
\hline Atmospheric model & Parametrizations & Initialization \\
\hline $\begin{array}{c}\text { Equations of motion: non-hydrostatic, } \\
\text { compressible Navier-Stokes } \\
\text { Horizontal } \\
\text { grid: Arakawa C-grid } \\
\text { grid points: } 125 \times 10 \\
\text { resolution: } 2 \mathrm{~km} \\
\text { Vertical } \\
\text { co-ordinate: } \sigma_{z} \text { terrain-following } \\
\text { grid: } 40 \text { levels } \\
\text { Resolution: } 5 \text { m, with a stretching } \\
\text { ratio of } 1.15, \text { so levels at } 5, \\
\text { 10.75, } 17.36, \ldots, 8895 \mathrm{~m} \\
\text { Lateral boundaries: radiative } \\
\text { condition following Klemp and } \\
\text { Wilhelmson (1978) } \\
\text { Vertical boundaries: damping in top } \\
\text { levels by Rayleigh friction }\end{array}$ & $\begin{array}{c}\text { Horizontal turbulence: local } \\
\text { deformation based on } \\
\text { two-dimensional strain } \\
\text { (with a minimum mixing coefficient) } \\
\text { Vertical turbulence: based on a } \\
\text { prognostic turbulent kinetic energy } \\
\text { scheme, the } 2.5 \text { level of Mellor } \\
\text { and Yamada (1974) } \\
\text { Surface layer } \\
\text { flux formulation: following Louis }(1979) \\
\text { Roughness length: } 1 \times 10^{-4} \mathrm{~m} \\
\text { (King } 1990) \\
\text { Scalar roughness length: } 9 \times 10^{-4} \mathrm{~m} \\
\text { (Cassano } \text { et al. } 2001) \\
\text { Radiation: long wave only, } \\
\text { based on Mahrer and Pielke (1977) } \\
\text { Microphysics: vapour phase only } \\
\text { Soil model: multi-layer } \\
\text { diffusion-based, adapted for firn } \\
\text { (compacted snow) }\end{array}$ & $\begin{array}{l}\text { Topography: uniform in the } \\
y \text { direction, from survey } \\
\text { by Peel (1976) } \\
\text { Atmosphere: horizontally } \\
\text { homogeneous initialization; } \\
\text { based on typical sounding } \\
\text { during 'katabatic conditions' } \\
\text { (7 May 1999) and at rest } \\
\text { Surface: temperatures from } \\
\text { remotely observed infrared } \\
\text { brightness temperatures } \\
\text { (King et al. } 1998 \text { ) } \\
\text { from } 7 \text { May 1999 } \\
\text { Soil: climatological for May, } \\
\text { lowest level held constant }\end{array}$ \\
\hline
\end{tabular}

${ }^{1}$ Regional Atmospheric Modeling System.

At the bottom boundary the atmospheric model interfaces with a multi-layer soil model. The soil model is essentially two diffusion equations, for temperature and moisture, with the thermal diffusivity being a function of soil type and moisture content. This has been adapted for use over compacted snow, and more details can be found in the appendix.

All simulations are initialized with a horizontally homogeneous atmosphere specified from a sounding of temperature, relative humidity and wind. The temperature profile is based on a sounding from Halley at 12 UTC 7 May 1999 that is typical of clear-sky conditions over Coats Land (King et al. 1998). The winds are set to zero and the relative humidity to $60 \%$. The initial surface 'soil' temperatures $\left(T_{\mathrm{sfc}}\right)$ are taken from infrared brightness temperatures $\left(T_{\mathrm{b}}\right)$ of the area from 1915 UTC 7 May 1999, again typical of clear-sky conditions, using techniques described in King et al. (1998). These have a relatively cold ice shelf, a warm 'thermal band' at the steepest part of the continental slope (Nakagawa and Shimodoori 1994), and a monotonic decrease in $T_{\mathrm{b}}$ with height continuing up the slope. Numerous wintertime model simulations have been carried out and a small selection of these are discussed here.

\section{A WINTERTIME DOWNSLOPE FLOW SIMULATION}

A typical wintertime downslope flow simulation lasting $48 \mathrm{~h}$ is illustrated here. Fig. 2 shows a cross-section of potential temperature $(\theta)$ at time $t=0 \mathrm{~h}$. Only part of the model domain is shown: the full width is from $x=-125$ to $+125 \mathrm{~km}$ and the full height reaches $8895 \mathrm{~m}$. Here $x, y$ and $z$ refer to the horizontal downslope, cross-slope and vertical directions respectively. The topography is that of Coats Land (from Peel 1976) and the adjacent Brunt Ice Shelf stretching from $x=30-80 \mathrm{~km}$, beyond which is $100 \%$ sea ice cover. Although fully three-dimensional (3D) simulations are carried out, 


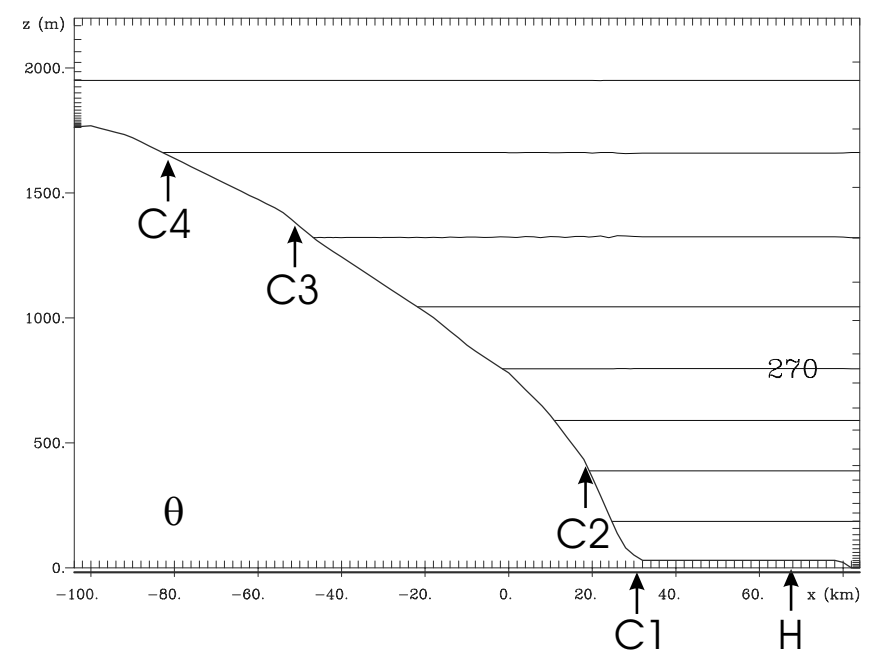

Figure 2. A vertical cross-section of potential temperature $(\theta)$ at time $t=0 \mathrm{~h}$, i.e. the initial conditions for the wintertime downslope flow simulation. The contour interval is $3 \mathrm{~K}$. The locations of Halley and the automatic weather station sites $\mathrm{C} 1$ to $\mathrm{C} 4$ are shown. Tick marks in the $x$ and $z$ directions indicate the horizontal and vertical grids.

the topography is uniform in the $y$ direction and so the simulations are $2 \mathrm{D}$ in character. As seen in Fig. 1, at this location the topography of Coats Land is approximately uniform across the slope. Annotated on Fig. 2 are the locations of Halley and four AWS sites, C1 to C4 (see Renfrew and Anderson 2002).

Figure 3 shows $\theta$, the downslope velocity $(u)$, the cross-slope velocity $(v)$, and the turbulent kinetic energy (TKE) after $24 \mathrm{~h}$ of model simulation. By this time, the net radiative-heat loss at the surface has led to strong surface cooling and the formation of a strongly stable surface layer. In the presence of a slope, this generates a downslope buoyancy forcing (i.e. a katabatic forcing) and the development of a shallow downslope flow. By $24 \mathrm{~h}$, this katabatic flow stretches from close to the crest to just beyond the foot of the slope. The katabatic layer is only $\sim 100 \mathrm{~m}$ in depth over the continental slope, while in the free atmosphere there is weak upslope flow. Over the ice shelf, the surface layer is deeper but $u$ is weaker. The katabatic flow is not directly downslope, there is a positive $v$ component due to the Coriolis force. The strongest cross-slope winds are approximately collocated with the strongest downslope winds. Over the slope, there is descent into the katabatic layer, as one would expect from continuity constraints (discussed in more detail later). There is a band of high TKE at the top of the katabatic layer, where shear production of TKE is large.

Figures 4-7, respectively, illustrate the evolution of the downslope flow via model soundings taken at Halley and the AWS sites C1, C2 and C3 (see Figs. 1 and 2). The locations are determined by matching model and observed station heights. Each figure shows $\theta, u$ and $v$ as functions of height above the surface at $0,12,24,36$ and $48 \mathrm{~h}$.

Examining the ice shelf sites Halley and C1 (Figs. 4 and 5), the $\theta$ profiles show the development of a strongly stable surface layer, on top of a general background cooling throughout the $500 \mathrm{~m}$ depth shown. The surface layer is formed as a result of downward sensible-heat flux into the snow surface-partially balancing the upward net radiativeheat flux. The background cooling is mainly a result of net radiative-heat loss to space. Over time and without any warm advection into the domain, this background cooling 
(a)

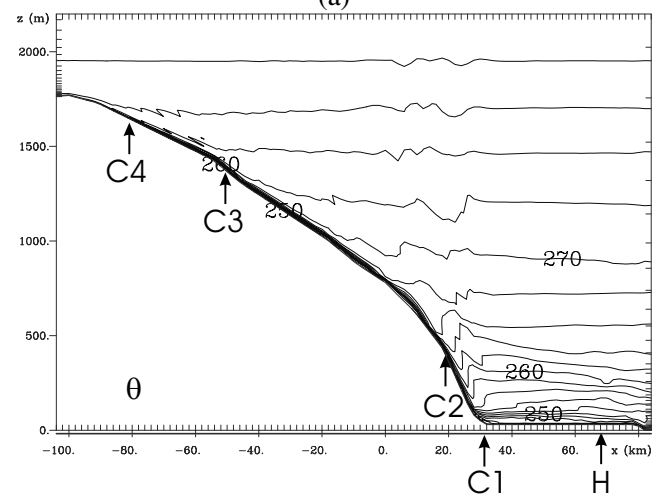

(c)

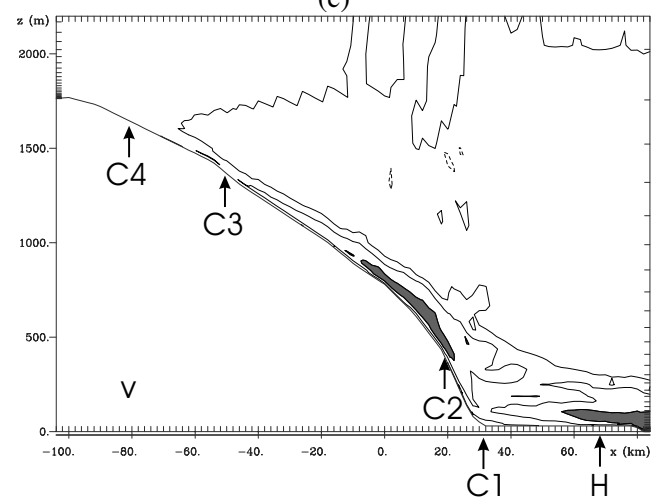

(b)

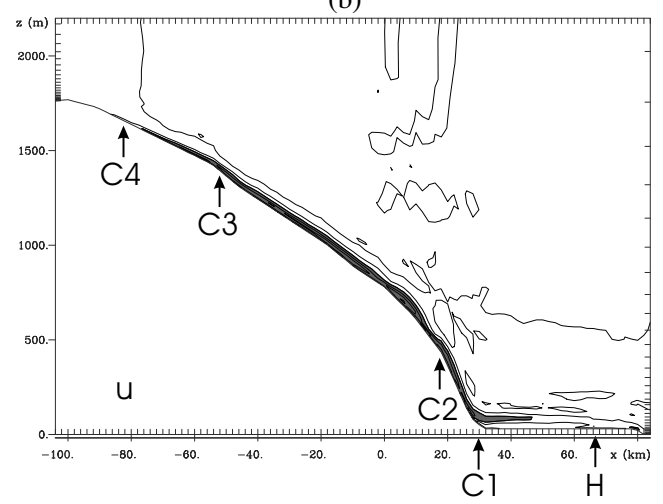

(d)

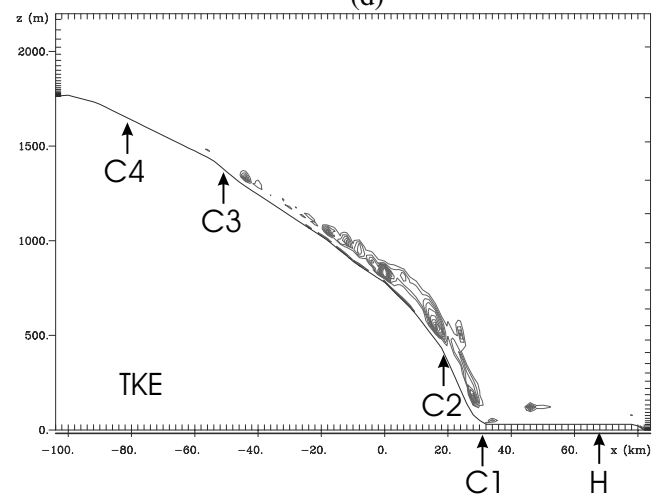

Figure 3. Cross-sections at time $t=24 \mathrm{~h}$ of: (a) potential temperature $\theta$; (b) wind component $u$; (c) wind component $v$; and (d) turbulent kinetic energy TKE. The contour intervals are $3 \mathrm{~K}, 2 \mathrm{~m} \mathrm{~s}^{-1}, 2 \mathrm{~m} \mathrm{~s}^{-1}$, and $0.04 \mathrm{~m}^{2} \mathrm{~s}^{-2}$ respectively. In (b) and (c) values greater than $4 \mathrm{~m} \mathrm{~s}^{-1}$ are shaded, and negative values have dashed contours.

will lead to an atmosphere that is unrealistically cold. By limiting the simulation to $48 \mathrm{~h}$ this model limitation becomes relatively unimportant for the results discussed here. Turning to the velocities, it is evident that there is a transient model response to the initial conditions and forcing. There is a well-defined jet in $u$ at $\mathrm{C} 1$ from 12-24 h, but it is fading by $36 \mathrm{~h}$, and is only $2 \mathrm{~m} \mathrm{~s}^{-1}$ by $48 \mathrm{~h}$. The katabatic flow retreats up the slope (past the $\mathrm{C} 1$ site) over the $48 \mathrm{~h}$ period. At Halley one can also see transient evidence of this flow in both $u$ and $v$, but by $48 \mathrm{~h} u$ is almost zero. Note that one would expect a backing of the flow on the ice shelf, relative to that on the slope, due to a change in the balance of forces, i.e. there is no downslope buoyancy forcing so a simple inertial balance (with frictional effects) should apply. By the end of the simulation the ice shelf sites have settled to low wind speeds.

Examining the continental slope sites (Figs. 6 and 7), a well-defined downslope flow develops after less than $12 \mathrm{~h}$ and is approximately steady over the rest of the $48 \mathrm{~h}$ period. At C2, close to the steepest part of the slope, the surface layer is around $100 \mathrm{~m}$ deep and is less stratified than over the ice shelf or further up the slope. Here the downslope flow peaks in a 6-7 $\mathrm{m} \mathrm{s}^{-1}$ jet at about $30 \mathrm{~m}$ above the surface. The total jet depth is just over $100 \mathrm{~m}$. The $v$ wind component increases with height through the surface layer as a result of the decreasing Ekman response to the surface. Interestingly, the height of the $v$ component 'jet' tends to increase with time from $\sim 200$ to $350 \mathrm{~m}$ 

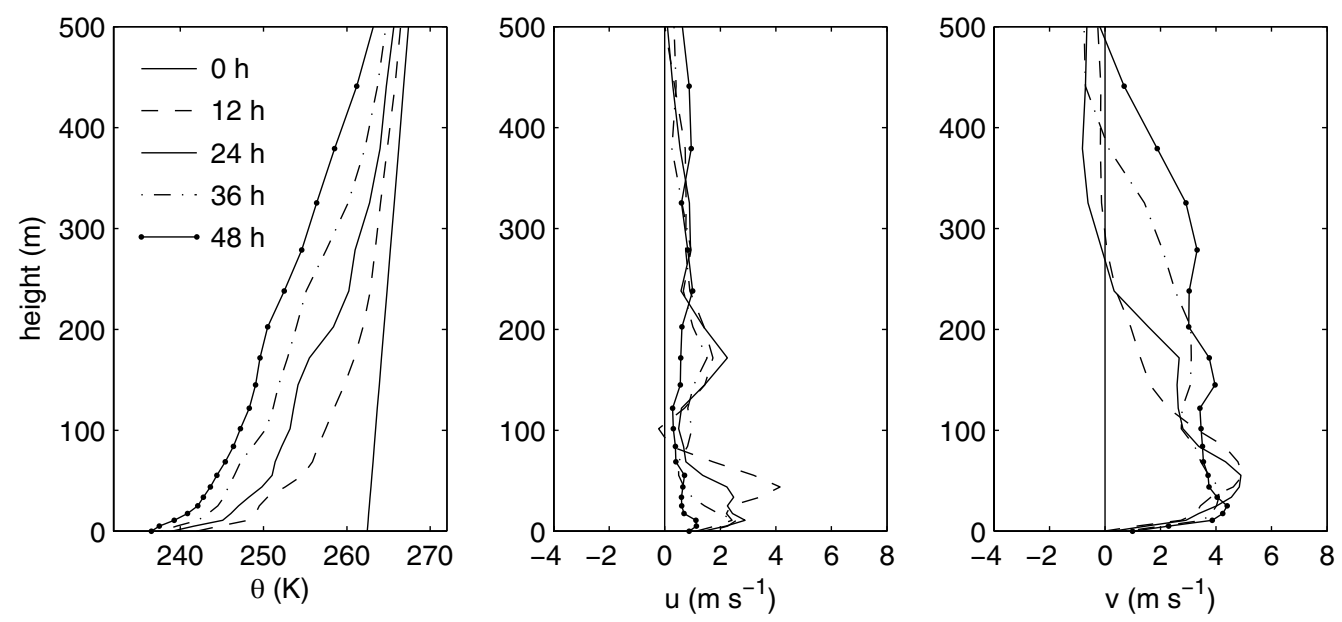

Figure 4. Model soundings of potential temperature $\theta$, and wind components $u$ and $v$ at Halley for times $t=0$, $12,24,36$ and $48 \mathrm{~h}$ of the simulation as indicated. Note the dots in the $48 \mathrm{~h}$ sounding indicate the model $\sigma_{z}$ levels.
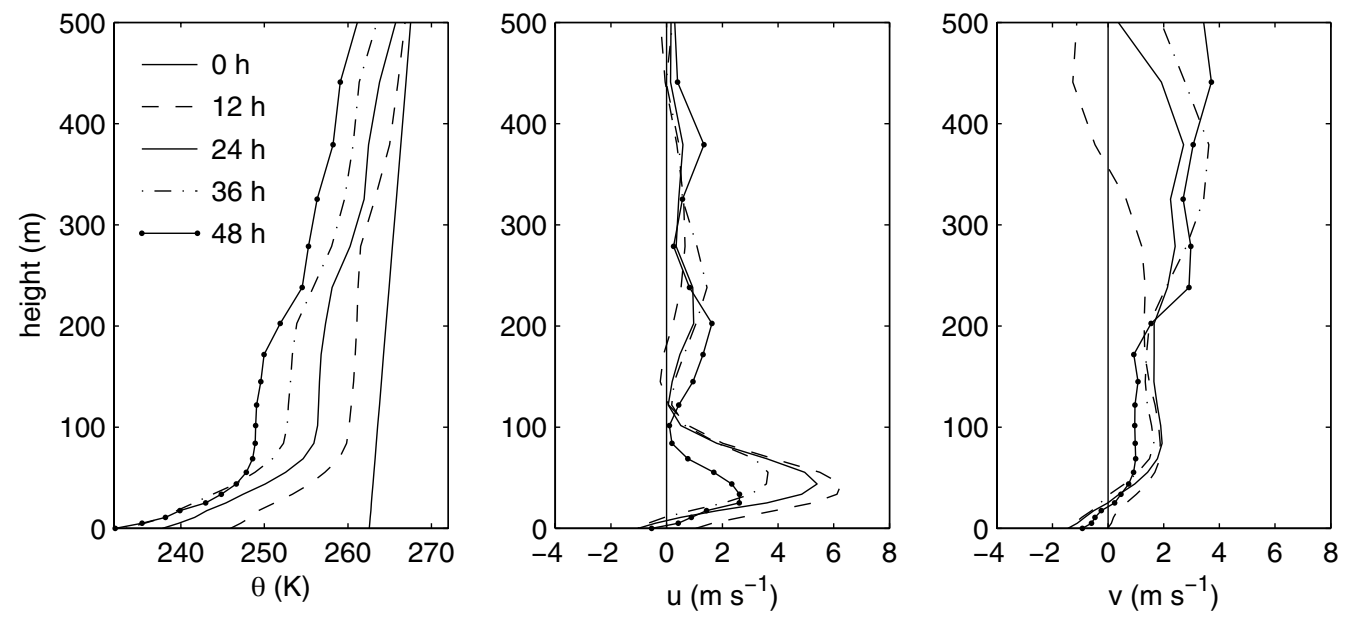

Figure 5. As Fig. 4 but for automatic weather station C1.

between 12 and $48 \mathrm{~h}$. This is a geostrophic response to the continuous cooling over the ice shelf (Figs. 4 and 5). The $v$ jet is approximately in thermal-wind balance with the downslope temperature field. Further up the slope, the katabatic flow is generally shallower with greater stability; for example, Fig. 7 shows $\theta, u$ and $v$ at $\mathrm{C} 3$, an altitude of $1400 \mathrm{~m}$. Here the katabatic layer is only around $50 \mathrm{~m}$ in depth and the jet peak in $u$ is only $15-20 \mathrm{~m}$ above the surface. The surface-layer potential-temperature deficit $(\Delta \theta)$ is larger here, $\sim 20 \mathrm{~K}$, compared to $\sim 15 \mathrm{~K}$ at $\mathrm{C} 2$. Further up the slope again at $\mathrm{C} 4$ (not shown) the flow is nearly invariant with time, shallow and much weaker (a maximum of $\sim 3 \mathrm{~m} \mathrm{~s}^{-1}$ ). Interestingly, the strongest modelled katabatic wind is further up the slope than $\mathrm{C} 2$ (see Fig. 3). At C2 the flow is already decelerating and deepening ahead of the quiescent ice shelf. Above the stable surface layer at $\mathrm{C} 2$ and $\mathrm{C} 1$, there is a near-neutral layer $(\partial \theta / \partial z \approx 0)$. This is generated through mixing by the band 

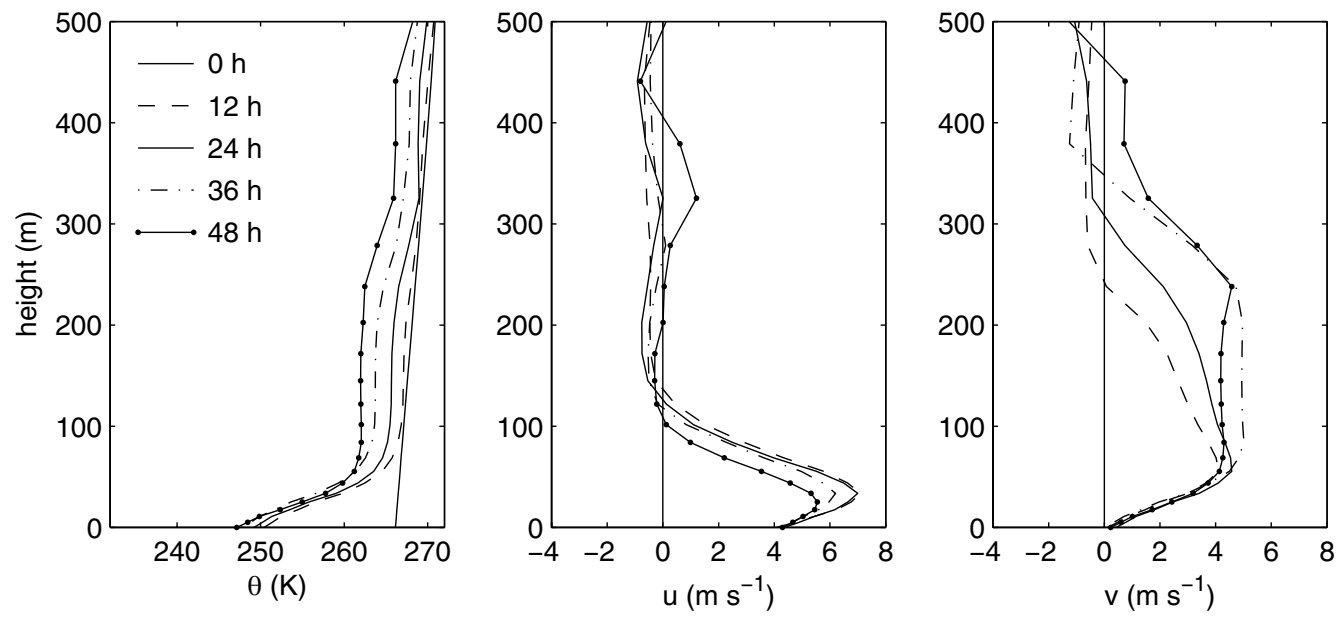

Figure 6. As Fig. 4 but for automatic weather station C2.
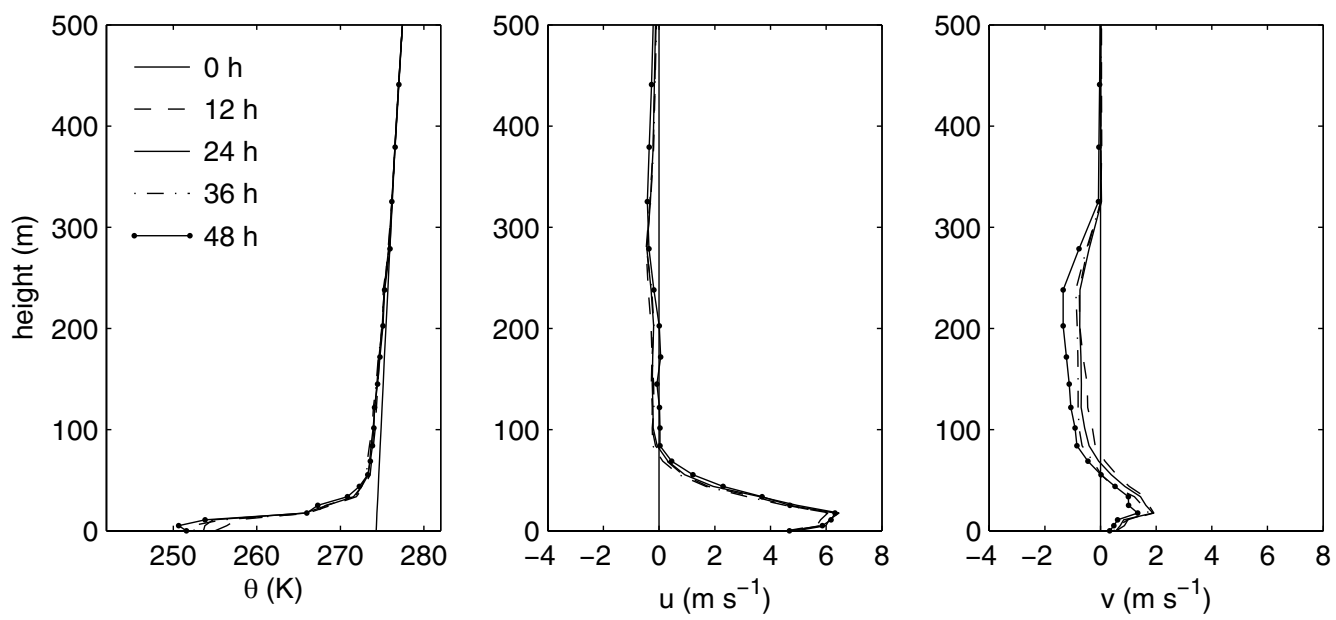

Figure 7. As Fig. 4 but for automatic weather station C3.

of high $T K E$ at the top of the katabatic layer (see Fig. 3). Similar near-neutral or unstable layers have been observed and modelled by Gallée and Pettré (1998) for example.

During the simulation, there are times when the atmosphere becomes temporarily statically unstable as a result of the advection of cold air over a relatively warm surface; for example, at $t=48 \mathrm{~h}$ at the $\mathrm{C} 3$ site (Fig. 7). This occurs because the rate of surface cooling is not uniform throughout the model domain, rather the surface temperature is a prognostic variable calculated from the model's surface energy balance. This means spatial differences in (for example) wind speed will lead to different surface sensible-heat fluxes, and thus different surface and near-surface temperatures. Advection can then lead to a statically unstable surface layer, the buoyant generation of $T K E$, and a mixing out of the instability to create a neutral layer. The mixing warms the near-surface atmosphere and so restores stability; which means the periods of static instability tend to be short-lived and the neutral layers vertically confined. In this 

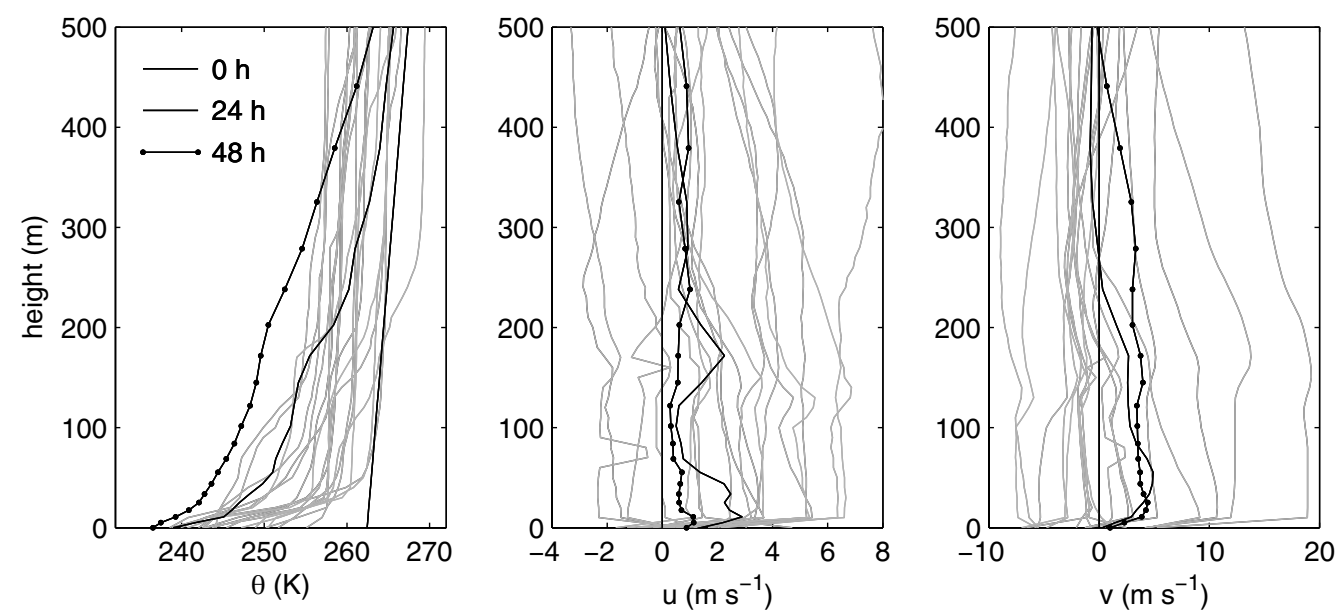

Figure 8. Model soundings of potential temperature $\theta$, and wind components $u$ and $v$ at Halley for times $t=0$, 24 and $48 \mathrm{~h}$ of the simulation as indicated, overlaid on radiosonde soundings at Halley during periods when there is katabatic flow at the automatic weather station $\mathrm{C} 2$ (see text for details).

series of idealized katabatic flow simulations such cold-air advection episodes often occur, hence an obvious question is-are they observed at Halley? A monostatic sodar (acoustic sounder) has operated at Halley for several years, and continuous backscatter returns from this are recorded and can be viewed as time-height echograms. Anderson (2003) investigates a number of interesting echograms with the aid of tethersonde profiles and surface data. He notes that elevated layers of high backscatter are frequently observed. The high backscatter layers can be the result of sharp temperature gradients, or layers of active or 'fossil' turbulence. These can be caused by, for example, convectively mixed marine boundary layers advected over Halley, or by solitons travelling across the Brunt Ice Shelf from the continent. It is possible that the cold-air advection mechanism modelled here is another cause of elevated high-backscatter layers in the sodar returns. Hence further case-study and modelling investigations are planned.

\section{WINTERTIME DOWNSLOPE FLOW VALIDATION AND SENSITIVITY}

A number of sensitivity tests have been performed for this idealized katabatic simulation, and in general the model flow response is robust. For example, there are no qualitative differences for minor changes to the initial conditions. For the Antarctic, sufficient quantities of sounding and surface observational data are available for model validation, and so some sensitivity experiments have been performed.

At Halley, daily upper-air radiosonde soundings are made as part of the station's operational meteorology programme. The validation data shown here are a subset of soundings that are deemed 'primarily katabatic', following the conditional sampling criteria developed by Renfrew and Anderson (2002). In this case, a sounding is included in the subset if most of that day and the $3 \mathrm{~h}$ surrounding the sounding time are primarily katabatic, as determined from the hourly surface data at C2 and Halley. For June, July and August 1998, this makes a subset of 21 days from which 18 soundings were available. Examining these soundings (Fig. 8) each has a well-defined strongly stable surface layer of depth 30-100 m, with $\Delta \theta$ of 10-20 K. A comparison with the modelled $\theta$ profiles at Halley (Fig. 8) and also at $\mathrm{C} 1$ (compare Figs. 5 and 8) is qualitatively 

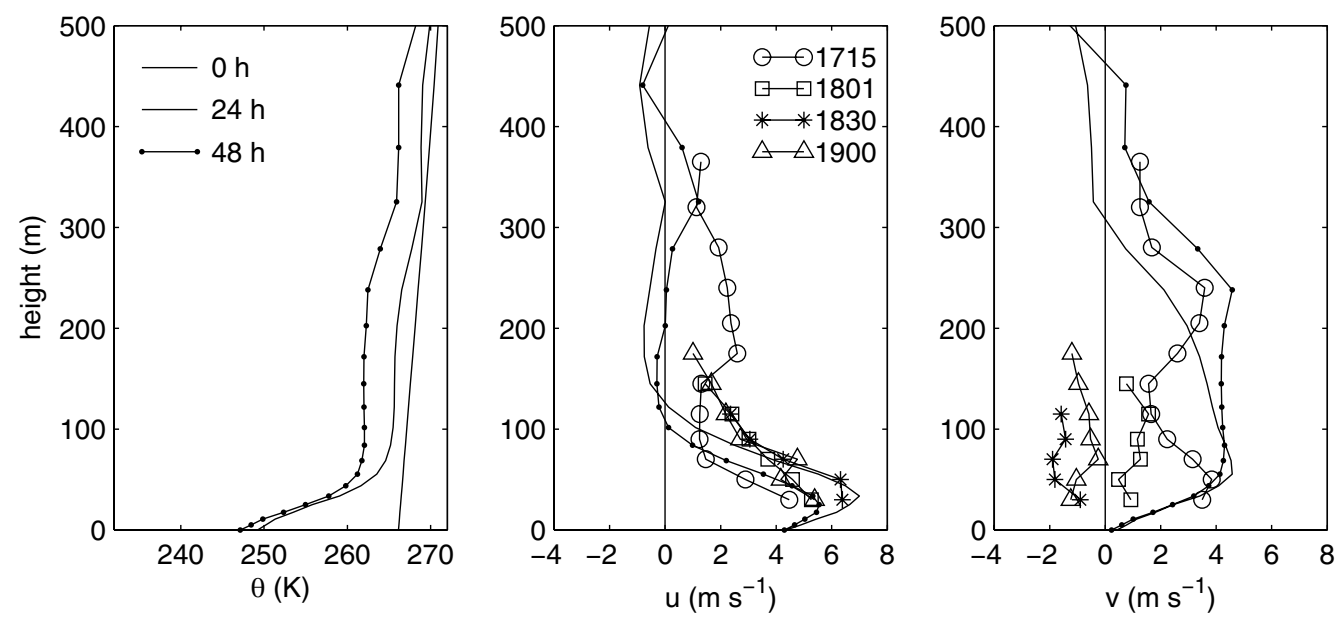

Figure 9. Model soundings of potential temperature $\theta$, and wind components $u$ and $v$ at automatic weather station $\mathrm{C} 2$ for times $t=0,24$ and $48 \mathrm{~h}$ of the simulation as indicated. Overlaid are four typical velocity profiles for apparently 'pure' katabatic flow on the 4 September 2002 (times as indicated). The velocity profiles are preliminary results from an autonomous Doppler sodar wind-profiling system.

good; the strength and depth of the stable surface layer is broadly captured, the only discrepancy is that the model is too cold later in the simulation time due to the general background cooling. The observed $u$ and $v$ soundings are much more varied over the conditionally sampled subset, with $u$ varying from -2 to $7 \mathrm{~m} \mathrm{~s}^{-1}$ and $v$ varying from -8 to almost $20 \mathrm{~m} \mathrm{~s}^{-1}$ over the lowest $500 \mathrm{~m}$. It would appear that the subset of observed soundings contains a range of background-flow environments, which make a detailed comparison with the modelled wind profiles inappropriate other than to comment that the simulated wind profiles fall towards the mean of the range that is observed. A feature that is common to many of the observed wind profiles is the weak elevated jet, or 'nose', in either $u$ or $v$ that is often located between 70 and $200 \mathrm{~m}$ in height (Fig. 8). There is a representation of this elevated jet in the model $u$ profile at $24 \mathrm{~h}$. Examining crosssections of $u$ and $v$ at various times (e.g. Figs. 3(b) and (c), and others not shown), it would appear that this subtle elevated jet is the tail end of a part of the katabatic flow that is riding up and over the cold (dense) atmospheric surface layer of the ice shelf and retreating up the continental slope over time. This elevated jet at Halley is a common feature of the model simulations.

Obtaining model validation data inland over the continental slope is considerably more difficult, due to the immense logistical problems of atmospheric sounding at a remote Antarctic field site. However, in January 2002 an autonomous Doppler sodar wind-profiling system was installed in Coats Land at the $\mathrm{C} 2$ site. At present this system is in its second of two years of planned observing at this location, and it is providing the first wintertime remote atmospheric soundings in the Antarctic continent. At this stage, not enough observations are available to provide a climatological context, so the soundings shown here should be viewed as 'typical' for what appear to be katabatic conditions. Plotted on Fig. 9 are four soundings from 4 September 2002, a day of clear skies and downslope winds on the continent. These profiles are representative of conditions when the winds above the boundary layer are light, that is, when it is inferred that the larger-scale flow is negligible and conditions are primarily katabatic. Making this 

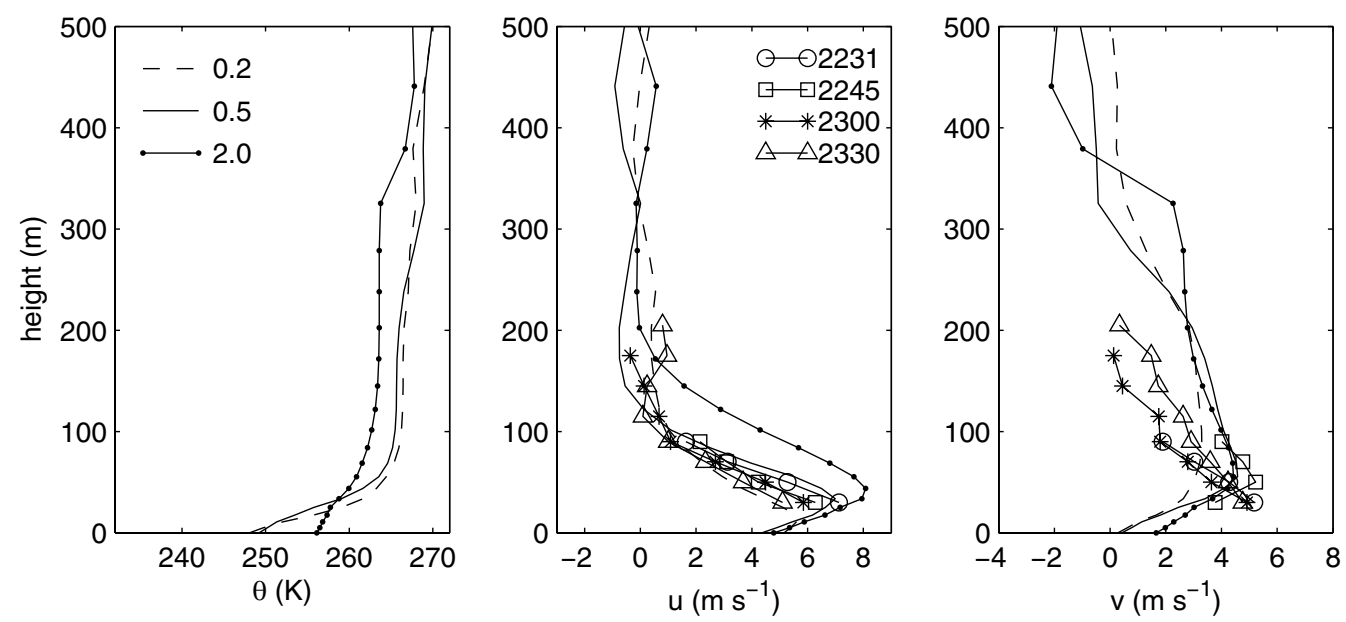

Figure 10. Model soundings of potential temperature $\theta$, and wind components $u$ and $v$ at automatic weather station $\mathrm{C} 2$ for time $t=24 \mathrm{~h}$ and three different simulations, where the ratio of the eddy diffusion coefficients $\left(K_{\mathrm{H}} / K_{\mathrm{M}}\right)$ was set to $0.2,0.5$ and 2.0 as indicated; $K_{\mathrm{H}} / K_{\mathrm{M}}=0.5$ is the standard setting. Overlaid are a further four typical velocity profiles for 'pure' katabatic flow on the 23 February 2002 (times as indicated).

assumption, the profiles should be directly comparable to the model soundings. The observations show a well-defined jet in $u$, with a maximum in the $20-40 \mathrm{~m}$ layer, and a jet top between 100-150 m. Over this 2-hour period, the downslope wind component is approximately steady, $u$ varies by only $\sim 1-2 \mathrm{~m} \mathrm{~s}^{-1}$ at any height and a comparison with the modelled $u$ is excellent. The observed $v$ decreases with time, in other words the winds veered. The model soundings correspond well to the 1715 UTC profile, but do not become negative at any stage and so are quite different from the later observations. It is probable that changes in the weak larger-scale flow, not represented in the model, influenced the observations.

Figure 10 provides another validation at $\mathrm{C} 2$, this time from 23 February 2002, a day seemingly dominated by katabatic flow, when there were clear skies and negligible winds aloft. Although these data are from the Antarctic summer, when the diurnal cycle is known to affect the katabatic flow (e.g. Gallée and Pettré 1998), the times plotted here are in the middle of the night when a katabatic flow is well-established. Indeed, over the 1-hour period shown the winds are remarkably steady. There is a welldefined katabatic jet in $u$, and above the jet a decreasing $v$ component with height. At 2245 UTC, the $v$ component shows the strong increase with height through the surface layer simulated in the model. The model soundings shown in Fig. 10 are all at $24 \mathrm{~h}$ but from three different simulations, with the only difference being a change in the turbulence parametrization (as discussed below). The comparison between the observed and modelled wind profiles in this case is extraordinarily good, particularly for the control $(0.5)$ simulation. Both the magnitude and shape of the katabatic jet are captured in the $u$ and $v$ model profiles. The only discrepancy is in the $v$ component, where the model $v$ jet is somewhat deeper than that observed. Recall, this is a geostrophic response to the ongoing cooling in the model and so the earlier $v$ profiles are expected to be closer to those observed.

Figure 10 illustrates a set of sensitivity experiments where the subgrid-scale turbulence parametrization has been changed. In the vertical the turbulence parametrization is 
TABLE 2. A COMPARISON OF NEAR-SURFACE WINDS, POTENTIAL TEMPERATURES AND POTENTIALTEMPERATURE GRADIENTS

\begin{tabular}{|c|c|c|c|c|c|c|c|c|c|c|}
\hline \multirow[b]{2}{*}{ Station } & \multicolumn{2}{|c|}{ Wind speed } & \multicolumn{2}{|c|}{ Wind direction } & \multicolumn{2}{|c|}{$\theta(\mathrm{K})$} & \multicolumn{4}{|c|}{$\Delta \theta / \Delta z\left(\mathrm{~K} \mathrm{~m}^{-1}\right)$} \\
\hline & obs. & model & obs. & model & obs. & model & obs. & model & $K_{\mathrm{H}} / K_{\mathrm{M}}=0.2$ & $K_{\mathrm{H}} / K_{\mathrm{M}}=2.0$ \\
\hline Halley & 3.3 & 1.8 & 188 & 147 & 246.6 & 240.0 & 0.87 & 0.6 & 0.6 & 0.5 \\
\hline $\mathrm{C} 2$ & 7.5 & 4.6 & 153 & 156 & 257.1 & 249.3 & 0.51 & 0.4 & 0.5 & 0.1 \\
\hline $\mathrm{C} 3$ & 5.1 & 4.8 & 139 & 155 & - & 254.2 & - & 0.9 & 1.4 & 0.5 \\
\hline $\mathrm{C} 4$ & 3.8 & 2.6 & 132 & 149 & 257.2 & 263.6 & 0.69 & 1.2 & 1.2 & 1.2 \\
\hline
\end{tabular}

The observations are for a conditionally sampled subset of katabatic data (from Tables 6 and 7 of Renfrew and Anderson 2002). The model data are for $3 \mathrm{~m}$ above the surface in the wintertime simulation (see Figs. 2-7), apart from the $\Delta \theta / \Delta z$ values which are surface-layer maxima. The C3 observations are not from the same subset of data as the other stations, hence only the winds are shown. The last two columns are for the sensitivity experiments illustrated in Fig. 10, where the diffusion coefficients are varied such that $K_{\mathrm{H}} / K_{\mathrm{M}}$ are 0.2 and 2.0 as indicated (recall the control simulation has $K_{\mathrm{H}} / K_{\mathrm{M}}$ set to 0.5 ).

of the one-and-a-half order closure type (e.g. Mellor and Yamada 1974; Garratt 1992); in this case the vertical diffusion coefficients are dependent on the TKE field, which in this model is a prognostic variable. In the horizontal a straightforward first-order $K$-theory formulation is used, with the momentum diffusion coefficient $\left(K_{\mathrm{M}}\right)$ a function of the local flow deformation (following Smagorinsky 1963). In this case, the scalar diffusion coefficient is calculated using a prescribed ratio, i.e. $K_{\mathrm{H}} / K_{\mathrm{M}}$ is prescribed where $K_{\mathrm{H}}$ is the scalar diffusion coefficient. Figure 10 shows $24 \mathrm{~h}$ model soundings at $\mathrm{C} 2$ for identical simulations, but with values of $K_{\mathrm{H}} / K_{\mathrm{M}}$ of $0.2,0.5$ and 2.0. Increasing the scalar diffusion results in a smaller $\Delta \theta$, a less-stable surface layer and a deeper, stronger downslope jet. The results are similar at $\mathrm{C} 3$, and to a lesser extent at $\mathrm{C} 1$ and Halley (not shown). As discussed above, a second set of Doppler sodar wind profiles are also plotted on Fig. 10 and it is clear that the best match to these is when $K_{\mathrm{H}} / K_{\mathrm{M}}=0.5$. When $K_{\mathrm{H}} / K_{\mathrm{M}}=0.2$ the downslope jet is too weak (peaking at only $\sim 5.5 \mathrm{~m} \mathrm{~s}^{-1}$ ), while for $K_{\mathrm{H}} / K_{\mathrm{M}}=2.0$ the downslope jet is too deep and the surface layer is not stable enough (see below). Similar results hold when comparing against observations from 24 February (not shown) and 9 September 2002 (Fig. 9).

Tuning the $K_{\mathrm{H}} / K_{\mathrm{M}}$ ratio has such a marked effect because of the nature of the simulation: the downslope flow is katabatically forced and so the boundary-layer potential-temperature distribution governs the velocity profiles. This suggests that these simulations provide a stiff test of the turbulence parametrization. Previous studies (e.g. Deardorff 1980) have suggested that $K_{\mathrm{H}} / K_{\mathrm{M}}$ should be up to 3 for convective conditions and down to 1 for stable conditions. Figure 10 suggests that the most realistic katabatic wind simulations require $K_{\mathrm{H}} / K_{\mathrm{M}}$ to be lower still, around 0.5 . Note that this is the value prescribed for the simulations discussed in sections 3 and 5 of this study.

Further model validation is provided by a comparison with the AWS-based surface climatology of Renfrew and Anderson (2002). Table 2 compares winds, temperatures and surface-layer stabilities. The observed data are conditionally sampled for katabatic conditions at the C2 site (taken from Tables 6 and 7 of Renfrew and Anderson (2002)). They are averages over several hundred hourly data and represent near-surface conditions during an archetypal katabatic flow in winter. The model data are means over $3 \mathrm{~h}$ (from 21-24 h) extracted at $3 \mathrm{~m}$ above the surface.

Qualitatively speaking, our model simulation compares well with the archetypal katabatic flow. Comparing the winds: the model captures the relatively high wind speeds at $\mathrm{C} 2$ and $\mathrm{C} 3$, and the lower wind speeds at Halley and $\mathrm{C} 4$, as well as the greater easterly component of the katabatic flow further up the slope at $\mathrm{C} 4$; however, at all stations the $3 \mathrm{~m}$ model wind speeds are too low. Comparing the potential temperatures: only station 
differences are discussed, as the absolute values are made somewhat irrelevant by the general background cooling of the model discussed earlier. The simulation of the $\theta$ difference between Halley and $\mathrm{C} 2$ is close to that observed $(10 \mathrm{~K})$. However the model fails to capture the approximately constant $\theta$ values observed at the continental sites during katabatic flow conditions - the higher continental sites are too warm. The model static stability is qualitatively correct with low values at C2 compared to Halley and higher up the slope. However, quantitatively the model stability is somewhat too low at Halley and C2, and too large at C4.

Model stabilities for the two sensitivity experiments discussed above (see Fig. 10) are also included in Table 2. In the low thermal diffusivity case $\left(K_{\mathrm{H}} / K_{\mathrm{M}}=0.2\right)$ the model stabilities are similar to those of the control case. At $\mathrm{C} 2$ the match to observations is better, but at $\mathrm{C} 3$ further up the slope the stability is unrealistically large. In the high thermal diffusivity case $\left(K_{\mathrm{H}} / K_{\mathrm{M}}=2.0\right)$ the stabilities are generally much lower than the other simulations and those observed. It is worth noting that quite small changes in this poorly known parametrization coefficient lead to large changes in the surfacelayer stability, illustrating the sensitive nature of these katabatic flow simulations to the parametrization of subgrid-scale turbulence.

The model validations have highlighted a number of quantitative deficiencies in the simulation, briefly:

- the near-surface wind speeds are too low;

- the surface layer is too stable towards the top of the slope.

The first of these may not be entirely due to model deficiencies, as it is certain that the conditionally sampled katabatic flow data will have (unintentionally) included periods when there is a background synoptically driven downslope forcing (Renfrew and Anderson 2002). This is acknowledged through a distinction between the primarily katabatic flows discussed in Renfrew and Anderson (2002) and the pure katabatic flows simulated here. In addition, however, it may be the case that the model's surface-layer parametrization is less than optimal for strongly stable conditions. This could explain both the low near-surface wind speeds and the high near-surface stabilities at the top of the slope. King (1990) analysed turbulence measurements at Halley and found that under extremely stable conditions the boundary layer can be as shallow as $50 \mathrm{~m}$, and furthermore, surface-layer similarity theory breaks down if the first evaluation point is above $\sim 10 \mathrm{~m}$. He presents wind profiles that show a significant departure from the standard logarithmic form that similarity theory suggests for neutral conditions-his observations show $2 \mathrm{~m}$ winds $\sim 10-20 \%$ higher than expected. Although our first model grid point is at $5 \mathrm{~m}$, it may still be the case that the model's surface-layer parametrization is breaking down or is inadequate. Using the first model-level wind and air temperature plus the surface temperature, a bulk Richardson number can be calculated. At $\mathrm{C} 4$ this is $\sim 0.3$, which is above the $\sim 0.25$ value of the critical Richardson number for the suppression of turbulence (Garratt 1992). This suggests that towards the top of the slope turbulence is being suppressed by the large near-surface stability. The model surface and atmosphere are close to becoming decoupled, in the sense that a turbulent (constant flux) surface layer is not adequately resolved by the model. A further investigation of the model's surface-layer parametrization is planned.

In summary: the wintertime downslope flow simulations illustrated here closely correspond to the archetypal and typical katabatic flows that have been observed in Coats Land, Antarctica. The comparison between modelled and observed potential temperatures and winds is remarkably good. The only definite model deficiency is a 
tendency for the surface layer to be too stable at the top of the slope. This problem does not impinge on the validity of the overall flow simulation.

\section{AN ANALYSIS OF THE KATABATIC FLOW DYNAMICS}

The forcing terms in the downslope momentum budget have been calculated following the framework set out in Mahrt (1982). This is similar to that used by Heinemann $(1999,2002)$ to investigate the dynamics of katabatic flows over Greenland. A two-layer model consisting of an active lower layer and a quiescent upper layer is assumed. The downslope momentum equation for the lower (katabatic) layer is:

$$
\frac{\mathrm{D} u_{\mathrm{kls}}}{\mathrm{D} t}=\frac{g \Delta \theta}{\theta_{0}} \sin \alpha-\cos \alpha \frac{g}{\theta_{0}} \frac{\partial\left(\Delta \theta h_{\mathrm{inv}}\right)}{\partial x}+f v_{\mathrm{kls}}-\frac{\partial \overline{\left(u^{\prime} w^{\prime}\right)}}{\partial z},
$$

where $u_{\mathrm{kls}}, v_{\mathrm{kls}}$, are katabatic-layer average velocities, $\theta_{0}$ is a reference potential temperature (here taken as the upper-layer $\theta$ ), $\Delta \theta$ is the potential-temperature deficit between the lower and upper layers (i.e. $\left.\Delta \theta=\theta_{0}-\theta_{\mathrm{kl}}\right), g$ is the gravitational acceleration, $\alpha$ is the positive slope angle, $f$ is the Coriolis parameter, and $h_{\text {inv }}$ is the height of the katabatic layer (defined below).

Note that in this section the coordinate system $(x, y, z)$ indicates directions downslope, cross-slope and perpendicular to the slope with the corresponding velocity components $\left(u_{\mathrm{kls}}, v_{\mathrm{kls}}, w_{\mathrm{kls}}\right)$. For the moderate slopes of the topography considered here $\sin \alpha \approx \alpha$ and $\cos \alpha=1$. Integrating over the katabatic layer and expanding the Lagrangian derivative gives:

$$
\begin{aligned}
\frac{\partial u_{\mathrm{kls}}}{\partial t}= & -\left(u_{\mathrm{kls}} \frac{\partial u_{\mathrm{kls}}}{\partial x}+w_{\mathrm{kls}} \frac{\Delta u_{\mathrm{kls}}}{h_{\mathrm{inv}}}\right)+\frac{g \Delta \theta}{\theta_{0}} \alpha-\frac{g h_{\mathrm{inv}}}{\theta_{0}} \frac{\partial \Delta \theta}{\partial x}-\frac{g \Delta \theta}{\theta_{0}} \frac{\partial h_{\mathrm{inv}}}{\partial x}+f v_{\mathrm{kls}} \\
& -\frac{\overline{u^{\prime} w_{\mathrm{inv}}^{\prime}}-\overline{u^{\prime} w^{\prime}}{ }_{\mathrm{sfc}}}{h_{\mathrm{inv}}}, \\
= & F_{\mathrm{adv}}+F_{\mathrm{b}}+F_{\Delta \theta}+F_{h}+F_{\mathrm{Cor}}+F_{\mathrm{div}},
\end{aligned}
$$

where $\Delta u_{\mathrm{kls}}$ is the difference between the upper and lower velocity (i.e. $\Delta u_{\mathrm{kls}}$ is negative). Here $F_{\text {adv }}$ is the total advection (i.e. the inertial force); $F_{\mathrm{b}}$ is the buoyancy (or katabatic) force; $F_{\Delta \theta}$ is due to the gradient in potential-temperature deficit; $F_{h}$ is due to the gradient in katabatic-layer height; $F_{\text {Cor }}$ is the Coriolis force; and $F_{\text {div }}$ is the momentum flux divergence force. $F_{\Delta \theta}$ and $F_{h}$ are often referred to as the 'thermal-wind forces', but as $F_{\mathrm{b}}$ is also related to thermal-wind effects this terminology is avoided here. $F_{\text {div }}$ is calculated from the vertical diffusion coefficients. In addition there is a forcing due to the downslope component of the model's horizontal diffusion; however this turns out to be negligible in these simulations and so is not discussed any further.

Mahrt (1982) defines the height of the slope flow to be when $p(h)=0$, i.e. the height at which the pressure perturbation associated with the buoyancy flow vanishes. Noting that $F_{\mathrm{b}}, F_{\Delta \theta}$ and $F_{h}$ in (2) disappear if there is no $\Delta \theta$, in practice this implies the height of the flow should be defined as the height of the temperature inversion, i.e. when $p\left(h_{\text {inv }}\right)=0$ is satisfied. Soundings of $u, v, \theta$ and $\partial \theta / \partial z$ were examined at each site, and a critical threshold chosen which unambiguously defines the top of the temperature inversion. For the wintertime simulations a threshold of $0.025 \mathrm{~K} \mathrm{~m}^{-1}$ is used (i.e. the katabatic flow has $\partial \theta / \partial z>0.025 \mathrm{~K} \mathrm{~m}^{-1}$ ). Values between 0.01 and $0.05 \mathrm{~K} \mathrm{~m}^{-1}$ were also tested and yielded similar results. Inversion-height variables are found by interpolating to the height of the critical $\partial \theta / \partial z$ threshold. A similar approach and threshold was employed by Heinemann (2002). 
Figure 11 shows time series of inversion height, $h_{\text {inv }}$, katabatic-layer average variables $\Delta \theta, u_{\mathrm{kl}}, v_{\mathrm{kl}}, w_{\mathrm{kl}}$ and $w_{\mathrm{kls}}$, where $w_{\mathrm{kl}}$ is the vertical velocity and $w_{\mathrm{kls}}$ is the slope-relative vertical velocity, and the kinematic momentum fluxes at the surface and inversion height $\overline{u^{\prime} w^{\prime}}$ sfc and $\overline{u^{\prime} w^{\prime}}$ inv, respectively. All of these variables are means over the $3 \mathrm{~h}$ period ending at the plotted time. At Halley an increase in $h_{\text {inv }}$ and $\Delta \theta$ over time is evident, while at the continental sites $h_{\mathrm{inv}}$ remains approximately constant. At $\mathrm{C} 1, \mathrm{C} 2$ and $\mathrm{C} 3, \Delta \theta$ is comparable-varying around $7 \mathrm{~K}$. The katabaticlayer velocities show a quasi-steady-state flow at $\mathrm{C} 2, \mathrm{C} 3$ and $\mathrm{C} 4$, but a deceleration at $\mathrm{C} 1$ as discussed earlier. The maximum downward velocities are at $\mathrm{C} 2$, as one would expect from continuity constraints. The vertical velocity perpendicular to the slope, $w_{\mathrm{kls}}$, is significantly different from zero only at $\mathrm{C} 1$ and $\mathrm{C} 2$; on their own, these generally positive values of $w_{\text {kls }}$ would lead to a deepening of the katabatic flow over time through mean vertical advection. This can be seen as Eqs. (1) and (2) constitute a zero-order jump model (e.g. see Garratt 1992) where the following expressions hold:

$$
\begin{aligned}
& \overline{u^{\prime} w^{\prime}} \text { inv }=\Delta u_{\mathrm{kls}}\left(\frac{\partial h_{\mathrm{inv}}}{\partial t}-w_{\mathrm{kls}}\right), \\
& {\overline{\theta^{\prime} w^{\prime}}}_{\mathrm{inv}}=\Delta \theta\left(\frac{\partial h_{\mathrm{inv}}}{\partial t}-w_{\mathrm{kls}}\right)
\end{aligned}
$$

with $\Delta u_{\mathrm{kls}}$ and $\Delta \theta$ the zero-order jumps at the katabatic-layer top. In the absence of inversion-level fluxes, i.e. $\overline{u^{\prime} w^{\prime}}$ inv and $\overline{\theta^{\prime} w^{\prime}}$ inv being zero, $h_{\text {inv }}$ is directly driven by $w_{\mathrm{kls}}$. This is not the situation here, rather at $\mathrm{C} 2$ and for most of the time at $\mathrm{C} 1 \partial h_{\text {inv }} / \partial t=0$ and the positive $w_{\mathrm{kls}}$ is balanced by a positive $\overline{u^{\prime} w^{\prime}}$ inv flux (Fig. 11) and a negative $\overline{\theta^{\prime} w^{\prime}}$ inv flux (not shown). In other words, there is entrainment of lower velocity (higher $\theta$ ) fluid from the free atmosphere into the katabatic flow.

It is interesting to note that in general, with this value of roughness length $\left(z_{0}=1 \times 10^{-4} \mathrm{~m}\right.$, Table 1) $\overline{u^{\prime} w^{\prime}}$ inv and $\overline{u^{\prime} w^{\prime}}$ sfc are the same order of magnitude (Fig. 11). That is to say, the frictional drag on the katabatic flow by the free atmosphere and by the surface are of similar size. Although dependent upon the model's parametrization of turbulence, this result implies the dynamics of the flow are more akin to those detailed in the hydraulic theory of Manins and Sawford (1979a,b) than in Ball (1956, 1960) where only surface friction is considered.

Figure 12 illustrates the forcing terms of the downslope momentum budget from Eq. (2). The terms are calculated using the $3 \mathrm{~h}$ mean data discussed above (Fig. 11). The illustration is after $24 \mathrm{~h}$ simulation time, but the results are representative of any time after $\sim 12 \mathrm{~h}$. It is clear that higher on the continental slope, at $\mathrm{C} 2, \mathrm{C} 3$ and $\mathrm{C} 4$, there is a balance between the advection term, $F_{\mathrm{adv}}$, and the buoyancy forcing $F_{\mathrm{b}}$. The $F_{\theta}$ and $F_{h}$ wind terms and the stress divergence generally retard the flow but are much smaller. The final term shown, $F_{\text {res }}$, is the residual of Eq. (2) and is due to approximations made in using this two-layer model to analyse a continuously stratified flow over a varying slope (the model is strictly only applicable for constant slopes, see Mahrt (1982))*. At $\mathrm{C} 1$, the foot of the slope, the balance of forces is quite different with $F_{\mathrm{b}}$ balanced by $F_{h}, F_{\Delta \theta}$ and $F_{\text {div }}$. The buoyancy force is balanced by a combination of upslope forcing primarily caused by the pool of cold air that forms over the ice shelf. This acts to dam the downslope flow, leading to the deceleration seen at C1 (Fig. 11). Given the archetypal nature of the simulation, this upslope forcing is thought to be the reason for the observed

\footnotetext{
* The residual also includes the Eulerian acceleration, but this is small, at $\mathrm{C} 1$ only $\sim-0.05 \times 10^{-3} \mathrm{~m} \mathrm{~s}^{-2}$.
} 

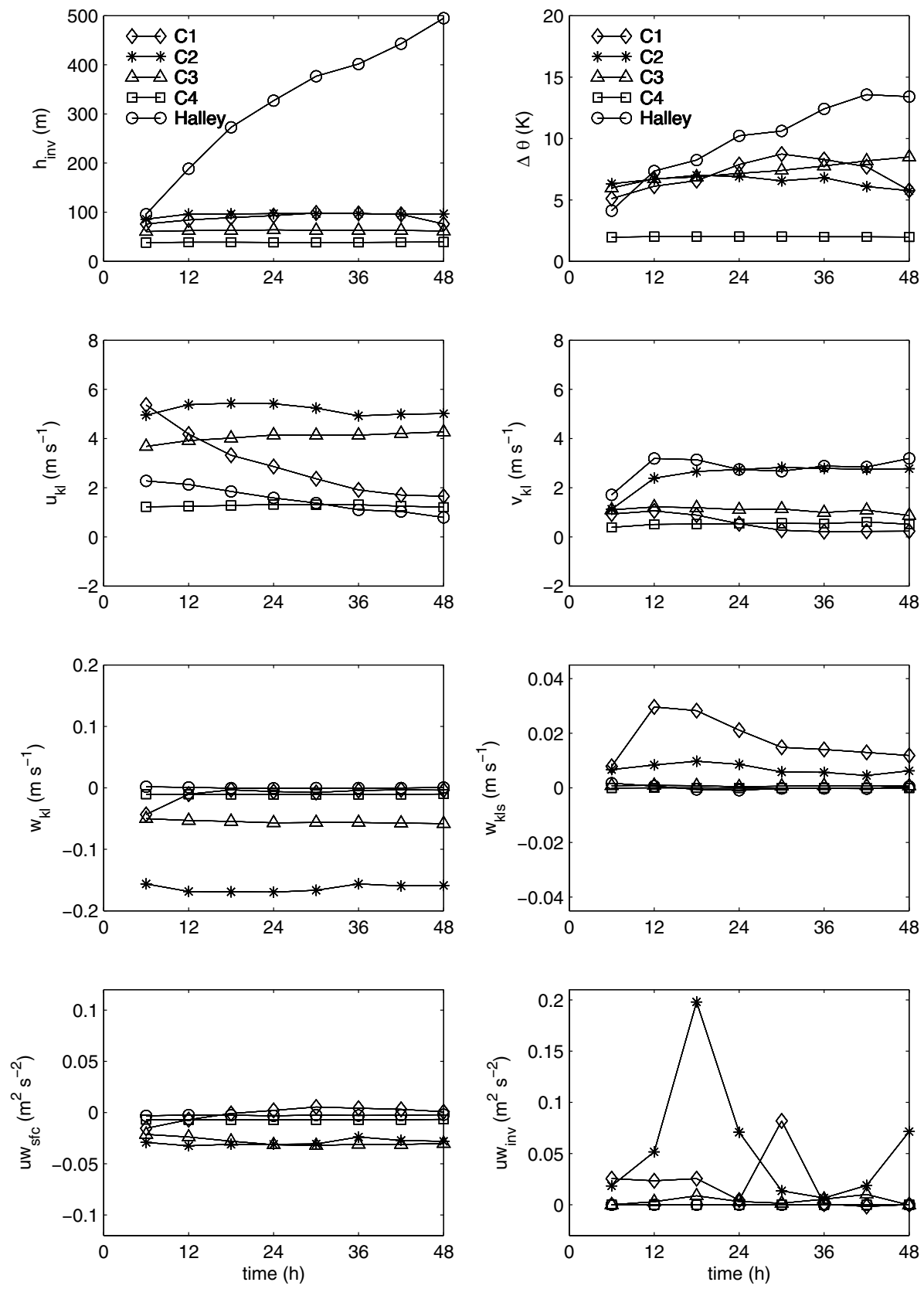

Figure 11. Model time series of katabatic-layer height $\left(h_{\mathrm{inv}}\right)$, katabatic-layer mean variables $\left(\Delta \theta_{\mathrm{kl}}, u_{\mathrm{kl}}, v_{\mathrm{kl}}, w_{\mathrm{kl}}\right.$, $w_{\mathrm{kls}}$ ), and surface and katabatic-layer top fluxes $\left(u w_{\mathrm{sfc}}\right.$ and $\left.u w_{\text {inv }}\right)$ at Halley and automatic weather stations $\mathrm{C} 1$ to C4. The variables are 3-hour means ending at the plotted time. 


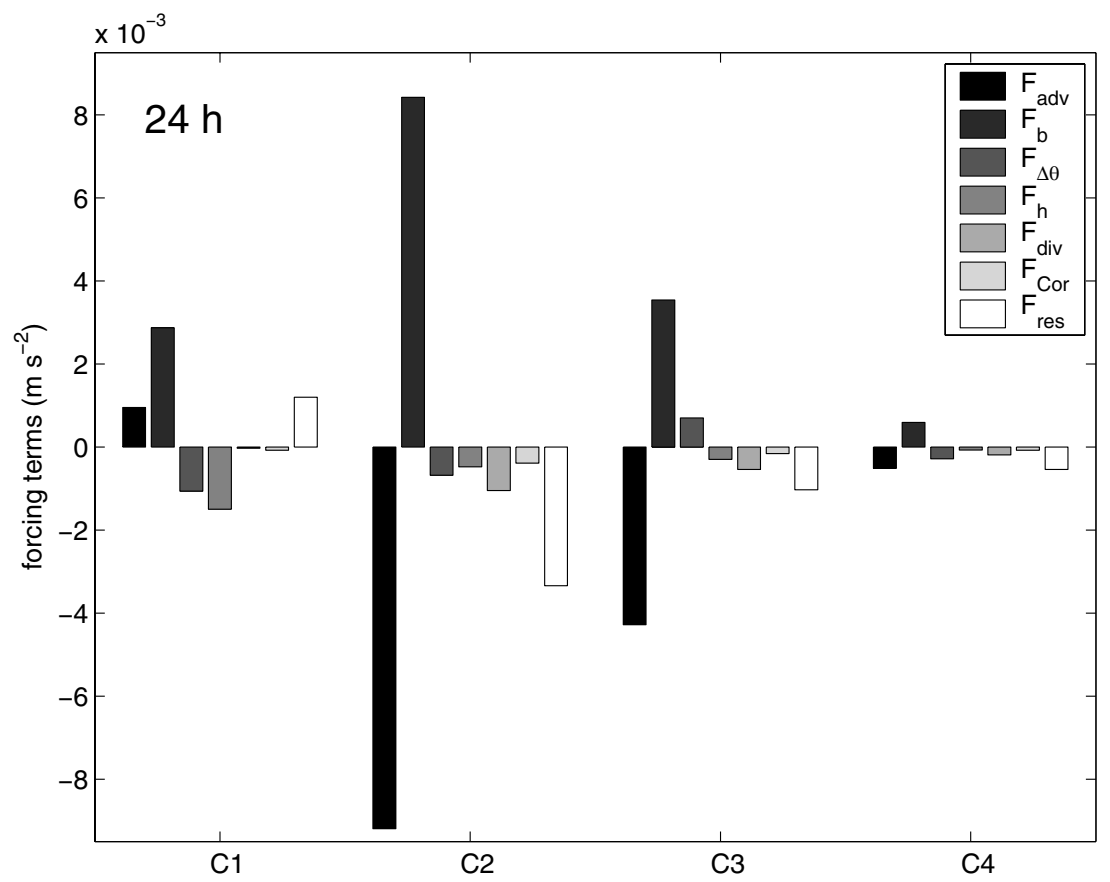

Figure 12. Forcing terms in the downslope momentum equation after $24 \mathrm{~h}$ simulation time: $F_{\text {adv }}$ is the advection term, $F_{\mathrm{b}}$ is the buoyancy force, $F_{\Delta \theta}$ is due to the gradient in potential-temperature deficit, $F_{h}$ is due to the gradient in katabatic-layer height, $F_{\text {div }}$ is the momentum flux divergence force, $F_{\text {Cor }}$ is the Coriolis force, and $F_{\text {res }}$ is the residual.

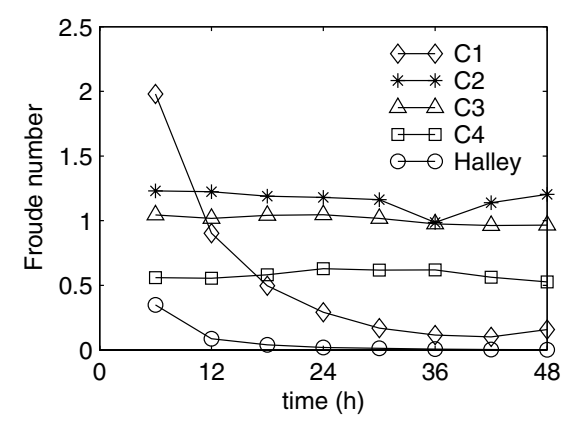

Figure 13. Model time series of Froude number at Halley and automatic weather stations C1 to C4 using 3-hour mean data.

difference in surface wind climatology on the slopes of Coats Land and the Brunt Ice Shelf discussed in the Introduction (see Fig. 1).

The two-layer analysis framework employed above allows the calculation of a local Froude number $(F r)$ :

$$
F r=\frac{u_{\mathrm{kls}}^{2}}{\left(g \Delta \theta / \theta_{0}\right) h_{\mathrm{inv}}} .
$$

In terms of hydraulic theory (e.g. Ball 1956; Mahrt 1982) the flow is 'shooting' if $F r>1$ and is 'tranquil' if $F r<1$. Figure 13 shows that, in this case, the katabatic flow moves from tranquil (C4) to shooting $(\mathrm{C} 2)$ to tranquil (C1/Halley) down the slope. 
(a)

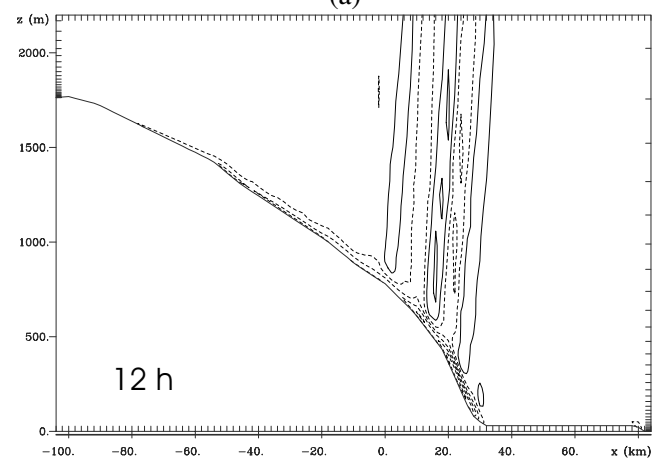

(c)

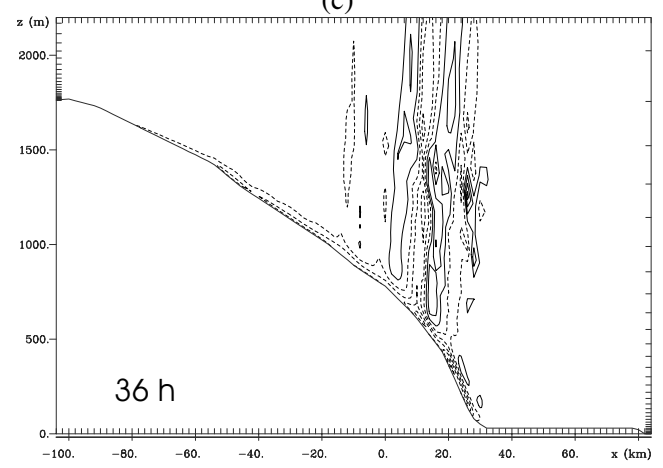

(b)

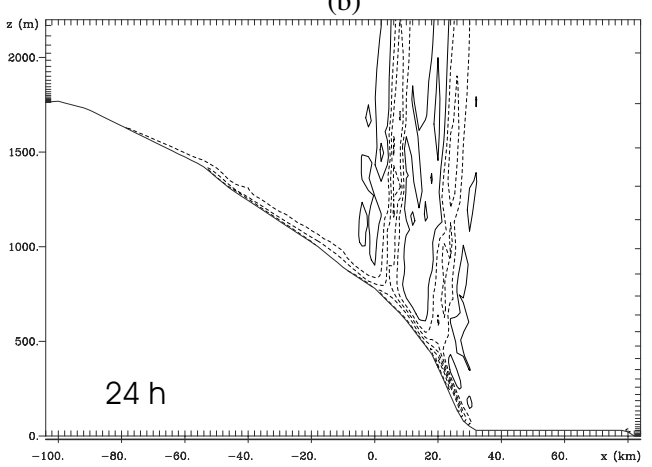

(d)

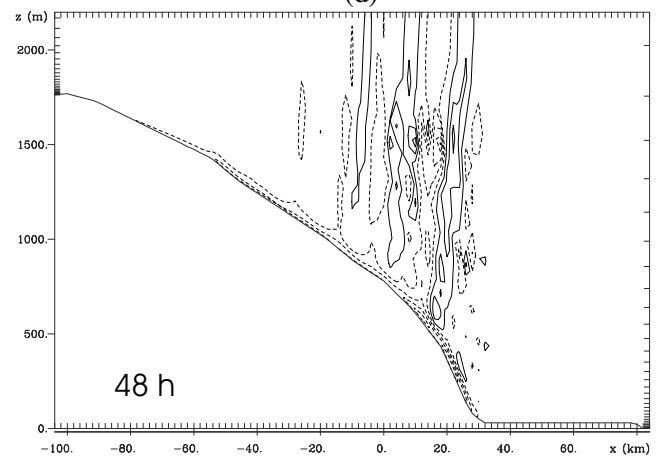

Figure 14. Cross-sections of vertical velocity $(w)$ at $12,24,36$ and $48 \mathrm{~h}$ as indicated. The contours are at $\ldots,-0.075,-0.025,0.025,0.075, \ldots \mathrm{m} \mathrm{s}^{-1}$ with negative contours dashed.

At $\mathrm{C} 2, \mathrm{Fr}$ is around 1 to 1.2 so it is only just in the shooting regime. At $\mathrm{C} 1$ the initially shooting flow becomes tranquil over time. In a strictly two-layer fluid flow these transitions of flow type would be through flow discontinuities or hydraulic jumps; indeed, such jumps have been observed in katabatic flows (e.g. Lied 1964; Pettré and André 1991). In this case the $F r$ variations are relatively small and, as the model is multi-level, the flow remains continuous.

A series of papers have modelled the cessation of katabatic flows over the somewhat steeper slopes of Adélie Land, Antarctica (Gallée and Schayes 1992; Gallée et al. 1996: Gallée and Pettré 1998). In these hydrostatic numerical simulations the flow changed from shooting to tranquil as the strong katabatic winds were blocked near the coast by an upslope pressure-gradient force caused by a 'piling up of cold air' over the ocean. These studies did not explicitly calculate all the forcing terms in Eq. (2) but, in the light of the results of Fig. 12, it is clear that an upslope forcing related to gradients in $\Delta \theta$ and $h_{\text {inv }}$ was in action. The more comprehensive later two studies were of summertime conditions, with open water off shore and a diurnal weakening of the katabatic flow adding to the upslope forcing. The Adélie Land simulations generally had a strong background synoptic forcing leading to downslope winds of $20 \mathrm{~m} \mathrm{~s}^{-1}$ or more, and thus a mechanically well-mixed katabatic layer.

There are similarities and differences to the situation in Coats Land. Over the more moderate slopes of Coats Land and without a background synoptic forcing the wind speeds are lower, and the katabatic layer retains a positive stability. In the wintertime Coats Land simulations the katabatic flow cessation is caused solely by cold-air 
damming, leading to upslope $F_{\Delta \theta}$ and $F_{h}$ forces, there are no diurnal effects. Furthermore, as the simulations are non-hydrostatic the transition from shooting to tranquil flow is modelled more realistically (Cassano and Parish 2000). This is demonstrated in Fig. 14 which shows cross-sections of vertical velocity, w, at 12, 24, 36 and $48 \mathrm{~h}$. Figure 14 shows there is descent into the shallow katabatic layer, as one would expect from continuity constraints, but also that there is a train of internal gravity waves over the continental slope. A comparison with contemporaneous cross-sections of $\theta$ shows a $\pi / 2$ phase lag - as one would expect from internal gravity waves. Furthermore, a rough calculation (e.g. Holton 1992) shows that with a horizontal wavelength $\sim 10 \mathrm{~km}$ and a Brunt-Väisälä frequency $\sim 4 \times 10^{-4} \mathrm{~s}^{-1}$, the horizontal phase speed should be $\sim 1 \mathrm{~m} \mathrm{~s}^{-1}$, consistent with the phase speed of the waves in the simulation. The gravity waves appear to be triggered near the foot of the slope-at the transition from shooting to tranquil flow. The horizontal phase speed of the waves is in the $x$ direction (i.e. upslope), consistent with an upward group velocity. This means the gravity waves are propagating energy upwards - away from the katabatic flow jump. All of the katabatic flow simulations carried out exhibit internal gravity waves, which suggests these are a common feature of katabatic flows over Coats Land. As the 2D topography used here is representative of much of coastal Antarctica, this suggests they are ubiquitous for areas prone to katabatic winds. A number of previous studies have also demonstrated a transition from shooting to tranquil flow near the coast of Antarctica (e.g. Gallée and Schayes 1992; Gallée et al. 1996: Gallée and Pettré 1998) but as these were hydrostatic studies the generation of internal gravity waves was not possible. To generalize the nonhydrostatic implications of this study suggests an active source of vertically propagating internal gravity waves around the Antarctic continent. If this is the case, there may be important implications for gravity-wave parametrization in large-scale numerical models.

\section{CONCLUSiOnS}

A state-of-the-art NWP model has been used to simulate idealized katabatic flows over a moderate slope and the adjoining ice shelf. The simulations are for wintertime clear-sky climatological conditions and are initialized with the atmosphere at rest. A shallow katabatic flow develops over the first $12 \mathrm{~h}$ or so, with approximately steady winds on the slope. The modest downslope jet has a peak of $\sim 7 \mathrm{~m} \mathrm{~s}^{-1}$ about $30 \mathrm{~m}$ above the surface and a total depth of 50 to $100 \mathrm{~m}$. There is a band of high TKE at the top of the katabatic layer. Over time the katabatic flow retreats from the ice shelf and some distance up the slope, while the ice shelf boundary layer cools. The pool of cold air causes an upslope forcing, proportional to the gradients in potential-temperature deficit and katabatic-layer height, which counteracts the downslope buoyancy forcing and decelerates the flow. At the transition the downslope flow changes from shooting to tranquil. This triggers a train of internal gravity waves which propagate energy upwards, away from the katabatic flow jump. To generalize these findings would suggest a source of internal gravity waves, as a by-product of katabatic flow deceleration, around much of coastal Antarctica and Greenland. This has implications for modelling the general atmospheric circulation and climate of these areas which clearly merits further study.

The model simulations have been validated against near-surface and sounding observations of archetypal and typical katabatic conditions in Coats Land and the adjoining Brunt Ice Shelf, Antarctica. The archetypal katabatic conditions are means of conditionally sampled subsets of data that have small perturbation pressure gradients and large stabilities (see Renfrew and Anderson 2002). The typical katabatic soundings are from 
radiosonde ascents at Halley and a novel autonomous Doppler sodar wind-profiling system in Coats Land. In general the model corresponds well to the observational data, capturing the scale and shape of the katabatic flow, especially after some tuning of the turbulence parametrization. In the horizontal, the scalar diffusion coefficient $\left(K_{\mathrm{H}}\right)$ is set as a constant proportion of the momentum diffusion coefficient $\left(K_{\mathrm{M}}\right)$, and it was found that $K_{\mathrm{H}} / K_{\mathrm{M}} \approx 0.5$ was optimal. It is suggested that the model's surface-layer parametrization (based on Louis 1979) may not be entirely adequate, as towards the top of the slope the surface-layer stabilities are too large and model turbulence is suppressed. In addition, the model's near-surface wind speeds may be too low. Occasionally $T K E$ is generated at the model's snow surface by cold-air advection, a process that results in persistent elevated neutral layers such as those that have been observed at Halley on the Brunt Ice Shelf.

\section{ACKNOWLEDGEMENTS}

I would like to thank Bob Walko, Craig Tremback and Marty Bell of ATMET as well as Xiaoming Cai and $\mathrm{Ye} \mathrm{Yu}$ at the University of Birmingham, for advice and support in running RAMS. I would also like to acknowledge useful discussions with John King, Phil Anderson and Nicole Van Lipzig, as well as the contributions made in obtaining the observational data of Russ Ladkin, Cathy Moore, and numerous Halley wintering personnel over recent years.

\section{APPENDIX}

The soil model is essentially two diffusion equations, for temperature and moisture, with the thermal diffusivity $\left(\kappa_{\mathrm{S}}\right)$ a function of soil type and moisture content (see McCumber and Pielke 1981; Garratt 1992). For example, the equation for soil potential temperature $\left(\theta_{\mathrm{s}}\right)$ is:

$$
\frac{\partial \theta_{\mathrm{s}}}{\partial t}=\frac{\partial}{\partial z}\left(\kappa_{\mathrm{s}} \frac{\partial \theta_{\mathrm{s}}}{\partial z}\right) .
$$

Note $\kappa_{\mathrm{S}}=k_{\mathrm{S}} / \rho_{\mathrm{s}} c_{\mathrm{S}}$, where $k_{\mathrm{s}}$ is thermal conductivity, $\rho_{\mathrm{S}}$ is the soil density and $c_{\mathrm{S}}$ is the soil specific-heat capacity (Garratt 1992).

The soil model was adapted for simulations over firn (compacted snow) and ice by the introduction of new 'soil' parameters (Table A.1). In other words, the approach taken is to assume that the firn/ice matrix is equivalent to a soil matrix. This means spaces in the matrix can be filled with liquid water if conditions allow, which therefore requires a specification of how water moves through the matrix. Following McCumber and Pielke (1981) and Clapp and Hornberger (1978) the hydraulic conductivity $\left(k_{\eta}\right)$, the moisture potential $(\psi)$, and the porosity, or volumetric moisture content, $(\eta)$ are calculated from simple relationships, after saturated values have been specified for that soil type-see Table A.1. The relationships also require a soil-dependent exponent $b$. Most of the new firn and ice parameters are from Morris (1991). Note that this approach makes the assumption that the firn/ice matrix remains intact and is not subject to mass loss through melting. This is not a problem in these model experiments as melting does not occur. Boundary conditions come from a prognostic surface energy balance equation at the surface, and constant values of temperature and moisture at the lowest level.

A number of other minor modifications to the RAMS model configuration have been implemented for simulations over snow/ice surfaces. For example, in calculating the surface moisture fluxes, relative humidity with respect to ice is used instead of 
TABLE A.1. PARAMETERS FOR THE FIRn (COMPACTED SNOW) AND ICE CATEgORIES OF THE RAMS SOIL MODEL ${ }^{1}$

\begin{tabular}{|c|c|c|c|c|c|c|c|}
\hline $\begin{array}{l}\text { 'Soil' } \\
\text { type }\end{array}$ & $\begin{array}{c}\text { 'Dry' } \\
\text { specific-heat } \\
\text { capacity } \\
c_{\mathrm{S}}\left(\mathrm{J} \mathrm{kg}^{-1} \mathrm{~K}^{-1}\right)\end{array}$ & $\rho_{\mathrm{s}}\left(\mathrm{kg} \mathrm{m}^{-3}\right)$ & $\begin{array}{c}\text { Thermal } \\
\text { conductivity } \\
k_{\mathrm{S}}\left(\mathrm{W} \mathrm{m}^{-1} \mathrm{~K}^{-1}\right)\end{array}$ & $\eta_{\mathrm{s}}\left(\mathrm{m}^{3} \mathrm{~m}^{-3}\right)$ & $\begin{array}{c}\text { Saturated } \\
\text { hydraulic } \\
\text { conductivity } \\
k_{\eta_{\mathrm{s}}}\left(\mathrm{m} \mathrm{s}^{-1}\right)\end{array}$ & $\begin{array}{c}\text { Saturated } \\
\text { moisture } \\
\text { potential } \\
\psi_{\mathrm{s}}(\mathrm{m})\end{array}$ & $b$ exponent \\
\hline firn & 2093 & 500 & 0.5 & 0.444 & 0.01 & 0.0244 & 1 \\
\hline ice & 2093 & 900 & 2.5 & 0.01 & 0.01 & 0.0244 & 1 \\
\hline
\end{tabular}

${ }^{1}$ See text for more details. Note that only the firn parameters are used in this study.

relative humidity with respect to water. Note that all the simulations discussed in the paper use the firn soil parameters.

Anderson, P. S.

Ball, F. K.

Bromwich, D. H.

Bromwich, D. H. and Liu, Z.

Bromwich, D. H., Du, Y. and Parish, T. H.

Cassano, J. J. and Parish, T. R.

Cassano, J. J., Parish, T. R. and King, J. C.

Clapp, R. and Hornberger, G.

Deardorff, J. W.

Gallée, $\mathrm{H}$.

Gallée, H. and Duynkerke, P.

1997

Gallée, H. and Pettré, P.

1998

Gallée, H. and Schayes, G.

1992

1994

Gallée, H., Pettré, P. and Schayes, G.

Garratt, J. R.

1996

1992

Heinemann, G.

1997

\section{REFERENCES}

2003 Fine-scale structure observed in a stable atmospheric boundary layer by sodar and kite-borne tethersonde. Boundary-Layer Meteorol., 107, 323-351

1956 The theory of strong katabatic winds. Aust. J. Phys., 9, 373-386

1960 Winds on the ice slopes of Antarctica. Pp. 9-16 in Antarctic meteorology, Pergamon Press, Oxford, UK

An extraordinary katabatic wind regime at Terra Nova Bay, Antarctica. Mon. Weather Rev., 117, 688-695

An observational study of the katabatic wind confluence zone near Siple Coast, west Antarctica. Mon. Weather Rev., 124, 462467

1994 Numerical simulation of winter katabatic winds from west Antarctica crossing the Siple coast and the Ross ice shelf. Mon. Weather Rev., 122, 1417-1435

An analysis of the nonhydrostatic dynamics in numerically simulated Antarctic katabatic flows. J. Atmos. Sci., 57, 891-898

Evaluation of turbulent surface flux parameterizations for the stable surface layer over Halley, Antarctica. Mon. Weather Rev., 129, 26-46

1978 Empirical equations for some soil hydraulic properties. Water Resour. Res., 14, 601-604

1980 Stratocumulus-capped mixed layers derived from a threedimensional model. Boundary-Layer Meteorol., 18, 495-527

Air-sea interactions over Terra Nova Bay during winter: Simulation with a coupled atmosphere-polynya model. J. Geophys. Res., 102, 13835-13849

Air-snow interactions and the surface energy and mass balance over the melting zone of west Greenland during GIMEX. J. Geophys. Res., 102, 13813-13824

Dynamical constraints on katabatic wind cessation in Adelie Land, Antarctica. J. Atmos. Sci., 55, 1755-1770

Dynamical aspects of katabatic wind evolution in the Antarctic coastal zone. Boundary-Layer Meteorol., 59, 141-161

Development of a three-dimensional meso-gamma primitive equation model: Katabatic winds simulation in the area of Terra Nova Bay, Antarctica. Mon. Weather Rev., 122, 671685

Sudden cessation of katabatic winds in Adélie Land, Antarctica. J. Appl. Meteorol., 35, 1147-1152

The atmospheric boundary layer. Cambridge University Press, Cambridge, UK

Idealized simulations of the Antarctic katabatic wind system with a three-dimensional mesoscale model. J. Geophys. Res., 102, $13825-13834$

1999 The KABEG '97 field experiment: An aircraft-based study of katabatic wind dynamics over the Greenland ice sheet. Boundary-Layer Meteorol., 93, 75-116 
Heinemann, G

2002

Holton, J. R.

1992

King, J. C.

1990

King, J. C., Varley, M. J. and Lachlan-Cope, T. A.

1998

Klemp, J. B. and Wilhelmson, R. B. 1978

Lied, N. T.

1964

Louis, J. F.

1979

McCumber, M. C. and Pielke, R. A. 1981

Mahrer, Y. and Pielke, R. A.

Mahrt, L.

Manins, P. C. and Sawford, B. L.

Mellor, G. L. and Yamada, T.

Morris, E. M.

Nakagawa, K. and Shimodoori, H.

1994

Parish, T. R.

1984

2001

Parish, T. R. and Bromwich, D. H.

1989

1998

Parish, T. R. and Waight, K. T.

Peel, D. A.

Pettré, P. and André J.-C.

Pielke, R. A.

Pielke, R. A., Cotton, W. R., Walko, R. L., Tremback, C. J., Lyons, W. A., Grasso, L. D., Nicholls, M. E., Moran, M. D., Wesley, D. A., Lee, T. J. and Copeland, J. H.
Modelling and observations of the katabatic flow dynamics over Greenland. Tellus 54A, 542-554

An introduction to dynamic meteorology. Third edition. Volume 48 International Geophysics Series, Academic Press, San Diego, USA

Some measurements of turbulence over an Antarctic ice shelf. Q. J. R. Meteorol. Soc., 116, 379-400

Control of near-surface winds over an Antarctic ice shelf. J. Geophys. Res., 98, 12949-12954

Using satellite thermal infrared imagery to study boundary layer structure in an Antarctic katabatic wind region. Int. J. Remote Sensing, 19, 3335-3348

The simulation of three-dimensional convective storm dynamics. J. Atmos. Sci., 35, 1070-1096

Stationary hydraulic jumps in a katabatic flow near Davis, Antarctica, 1961. Aust. Meteorol. Mag., 47, 40-51

A parametric model of vertical eddy fluxes in the atmosphere. Boundary-Layer Meteorol., 17, 187-202

Simulation of the effects of surface fluxes on heat and moisture in a mesoscale numerical model. 1: Soil layer. J. Geophys. Res., 86, 9929-9938

A numerical study of the airflow over irregular terrain. Beit. Phys. Atmos., 50, 98-113

1982 Momentum balance of gravity flows. J. Atmos. Sci., 39, 27012711

1979a Katabatic winds: A field case-study. Q. J. R. Meteorol. Soc., 105, 1011-1025

1979b A model of katabatic winds. J. Atmos. Sci., 36, 619-630

1974 A hierarchy of turbulence closure models for planetary boundary layers. J. Atmos. Sci., 31, 1791-1806

Physics-based models of snow. Pp. 85-112 in Recent advances in the modeling of hydrologic systems. Eds. D. S. Bowles and P. E. O'Connell. Kluwer Academic Publishers, Dordrecht, the Netherlands

'The relationship between the thermal belt on the slope of the ice sheet on the Soya coast and the surface inversion layer over Syowa station'. Pp. 53-65 in volume 8 of Proceedings of the NIPR Symposium on polar meteorology and glaciology. National Institute of Polar Research, Tokyo, Japan

A numerical study of strong katabatic winds over Antarctica. Mon. Weather Rev., 112, 545-554

'Topographic forcing of the Antarctic wind field'. Pp. 355-358 in Proceedings of the sixth conference on polar meteorology and oceanography, San Diego, CA. American Meteorological Society, Boston, MA

Instrumented aircraft observations of the katabatic wind regime near Terra Nova Bay. Mon. Weather Rev., 117, 1570-1585

Continental-scale simulation of the Antarctic katabatic wind regime. J. Climate, 4, 135-146

A case study of Antarctic katabatic wind interaction with largescale forcing. Mon. Weather Rev., 126, 199-209

1976 Snow accumulation, conductance and temperature inland from Halley Bay. British Antarctic Survey Bull., 43, 1-13

1991 Surface-pressure change through Loewe's phenomena and katabatic flow jumps: Study of two cases in Adelie Land, Antarctica. J. Atmos. Sci., 48, 557-571

2002 Mesoscale meteorological modeling. Second edition. Volume 78, International Geophysics Series, Academic Press, San Diego, USA

1992 A comprehensive meteorological modeling system-RAMS. Meteorol. Atmos. Phys., 49, 69-91 
Renfrew, I. A. and Anderson, P. S. 2002 The surface climatology of an ordinary katabatic wind regime in

Smagorinsky, J.

1963 General circulation experiments with the primitive equations.

Van den Broeke, M. R.,

Van Lipzig, N. P. M. and

Van Meijgaard, E.

2002 Momentum budget of the east-Antarctic atmospheric boundary

layer: Results of a regional climate model. J. Atmos. Sci., 59, 3117-3129 